\title{
Wind-Tunnel Development of an SR-71 Aerospike Rocket Flight Test Configuration
}

Timothy R. Moes, Brent R. Cobleigh, Timothy R. Conners, Timothy H. Cox, Stephen C. Smith, and Norm Shirakata

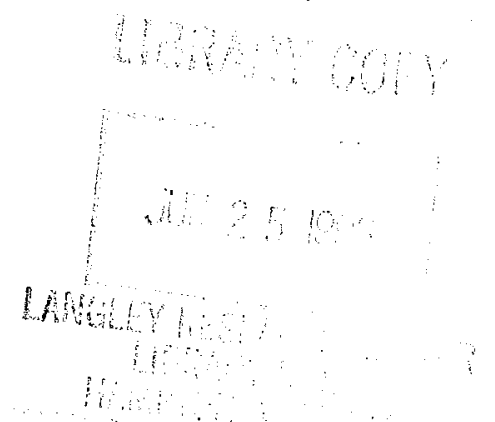

FOR REFEREMCE NOT TO BE TAKEN FROH THIS ROOH

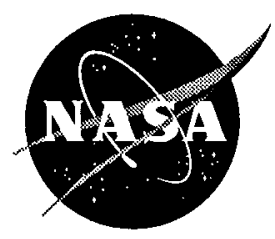

National Aeronautics and

Space Administration 


\section{Wind-Tunnel Development of an SR-71 Aerospike Rocket Flight Test Configuration}

Timothy R. Moes, Brent R. Cobleigh,

Timothy R. Conners, and Timothy H. Cox

NASA Dryden Flight Research Center

Edwards, California

Stephen C. Smith

NASA Ames Research Center

Moffett Field, California

Norm Shirakata

Lockheed-Martin Skunk Works

Palmdale, California

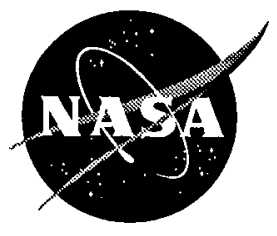

National Aeronautics and

Space Administration

Dryden Flight Research Center

Edwards, California 93523-0273 


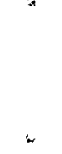




\title{
WIND-TUNNEL DEVELOPMENT OF AN SR-71 AEROSPIKE ROCKET FLIGHT TEST CONFIGURATION
}

\author{
Timothy R. Moes, ${ }^{*}$ Brent R. Cobleigh, ${ }^{*}$ \\ Timothy R. Conners, ${ }^{*}$ and Timothy H. Cox ${ }^{\dagger}$ \\ NASA Dryden Flight Research Center \\ Edwards, California \\ Stephen C. Smith, ${ }^{*}$ \\ NASA Ames Research Center \\ Moffett Field, California \\ Norm Shirakata ${ }^{\ddagger}$ \\ Lockheed-Martin Skunk Works \\ Palmdale, California
}

\begin{abstract}
A flight experiment has been proposed to investigate the performance of an aerospike rocket motor installed in a lifting body configuration. An SR-71 airplane would be used to carry the aerospike configuration to the desired flight test conditions. Wind-tunnel tests were completed on a 4-percent scale SR-71 airplane with the aerospike pod mounted in various locations on the upper fuselage. Testing was accomplished using sting and blade mounts from Mach 0.6 to Mach 3.2. Initial test objectives included assessing transonic drag and supersonic lateral-directional stability and control. During these tests, flight simulations were run with wind-tunnel data to assess the acceptability of the configurations. Early testing demonstrated that the initial configuration with the aerospike pod near the SR-71 center of gravity was unsuitable because of large nosedown pitching moments at transonic speeds. The excessive trim drag resulting from accommodating this pitching moment far exceeded the excess thrust capability of the airplane. Wind-tunnel testing continued in an attempt to find a configuration suitable for flight test. Multiple configurations were tested. Results indicate that an aft-mounted model configuration possessed acceptable performance, stability, and control characteristics.
\end{abstract}

\footnotetext{
*Acrospace Engincer. AIAA member.

†Aerospace Engineer.

${ }^{\ddagger}$ Retired Aerospace Engineer.

Copyright $(1996$ by the American Institute of Aeronautics and Astronautics, Inc. No copyright is asserted in the United States under Title 17, U.S. Code. The U.S. Government has a royalty-free license to exercise all rights under the copyright claimed herein for Governmental purposes. All other rights are reserved by the copyright owner.
}

\section{$\underline{\text { Nomenclature }}$}

B.L. butt line, in

$C_{D} \quad$ drag coefficient

$C_{L} \quad$ lift coefficient

$C_{l} \quad$ rolling moment coefficient (stability axis)

$C_{m} \quad$ pitching moment coefficient

$C_{m_{0}} \quad$ zero lift pitching moment coefficient

$C_{n} \quad$ yawing moment coefficient (stability axis)

$C_{p} \quad$ surface pressure coefficient

$C_{Y} \quad$ side force coefficient

c.g. center of gravity

DFRC NASA Dryden Flight Research Center, Edwards, California

F.S. fuselage station, in.

KEAS equivalent airspeed, $\mathrm{kn}$

LASRE Linear Aerospike SR-71 Experiment

$M \quad$ Mach number

m.a.c. mean aerodynamic chord

NTS National Technical Systems

SSTO single stage to orbit

W.L. waterline

$\alpha \quad$ wing reference plane angle of attack, deg

$\beta \quad$ angle of sideslip, deg

$\Delta \quad$ increment from baseline SR-71 aircraft 
$\delta e$

elevon deflection, deg

$\delta r$

rudder deflection, deg

Aerodynamic Model Reference Quantities

$b_{\text {ref }} \quad$ reference span, $56.7 \mathrm{ft}$

$c_{\text {ref }} \quad$ reference chord $=$ m.a.c., $37.7 \mathrm{ft}$

$S_{\text {ref }} \quad$ reference area, $1605 \mathrm{ft}^{2}$

$X_{\text {ref }} \quad$ longitudinal moment reference, F.S. 900

( 25 percent m.a.c.)

$Y_{\text {ref }} \quad$ lateral moment reference, B.L. 0

$Z_{\text {ref }} \quad$ vertical moment reference, W.L. 100

\section{Introduction}

Recent emphasis on single-stage-to-orbit (SSTO) vehicle technology has led the National Aeronautics and Space Administration (NASA) to request proposals for an SSTO Technology Demonstrator Flight Vehicle which has become known as the X-33. A contractor team, led by Lockheed-Martin Corporation, Marrietta, Georgia, developed an X-33 concept which incorporates a linear aerospike rocket engine in a lifting body vehicle configuration. The aerospike rocket was first developed and ground tested in the 1960's. ${ }^{1,2}$ The principle advantage of the aerospike rocket is the inherent altitude compensation provided by the nozzle. This compensation results in increased specific impulse performance during the low-altitude portion of a flight when compared to a conventional bell nozzle rocket (fig. 1). Altitude compensation is a result of the plume being able to expand to the slipstream static pressure. The slipstream pressure, however, is necessarily reduced because of flow expansion around the rocket nozzle cowl. This decrease in pressure causes the plume to overexpand slightly; hence, an expected loss of performance occurs. This phenomenon has been labeled the "slipstream effect" and is dependent on the configuration, Mach number, chamber pressure ratio, and Reynolds number.

In an effort to obtain data for the X-33 concept, Lockheed-Martin and Rocketdyne, Canoga Park, California (builder of the aerospike rocket), initiated a program with NASA to flight test the aerospike rocket engine using an SR-71 airplane as the carrier vehicle in a project known as the Linear Aerospike SR-71 Experiment (LASRE). The aerospike rocket and its associated components, referred to as the aerospike pod. will be mounted on the SR-71 upper fuselage surface centerline. Figure 2 shows the pod installation on the wind-tunnel model. Note that the vertical tails of the SR-71 airplane were removed for this photograph. The aerospike pod components are referred to as the canoe, kayak, reflection plate, and a half-span model of a lifting body configuration. The canoe is installed on the SR-71 fuselage and contains the gaseous hydrogen fuel and liquid water needed for cooling. The kayak, located beneath the reflection plate and on top of the canoe, is used to incline the model at a $2^{\circ}$ nosedown incidence angle. This angle aligns the lower part of the model with the local flow over the top of the SR-71 airplane. The
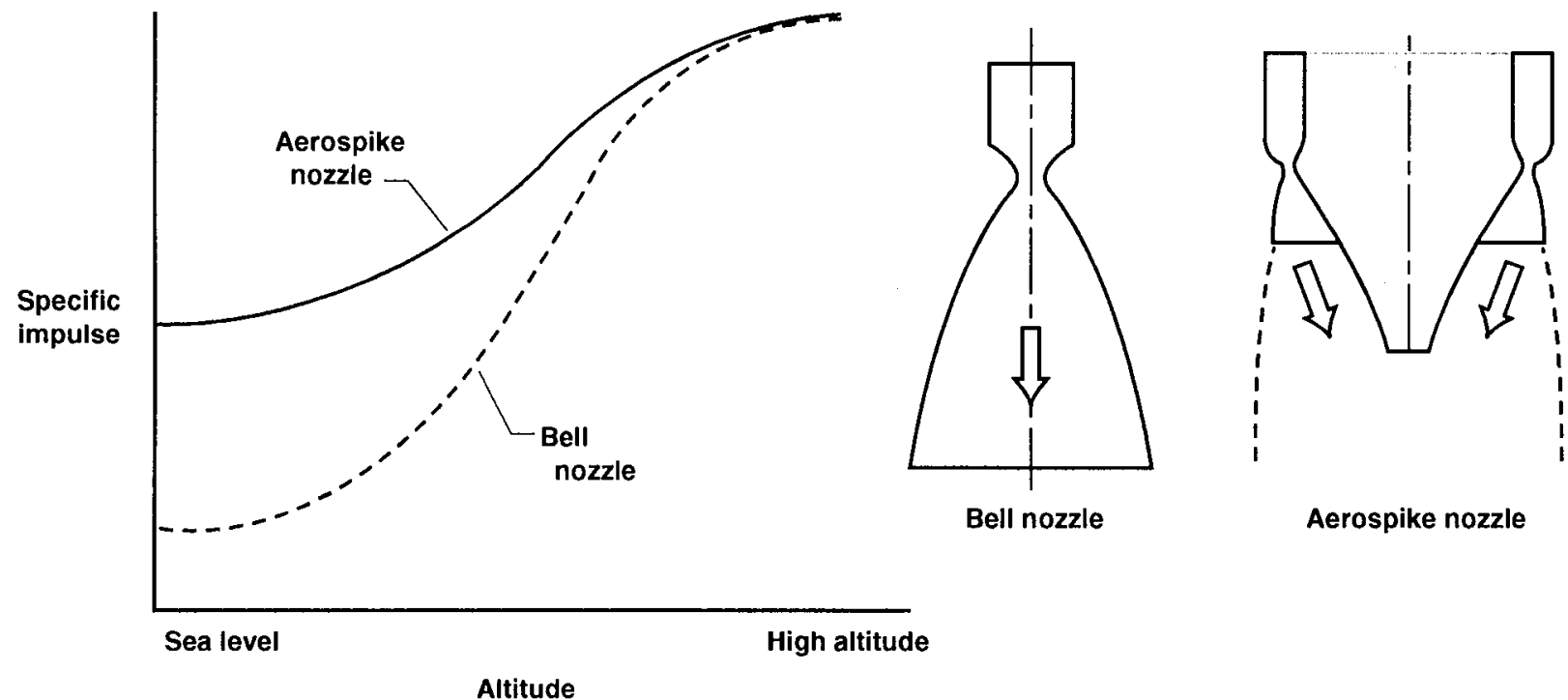

Altitude

Figure 1. Qualitative comparison of aerospike and bell nozzle specific impulse. 


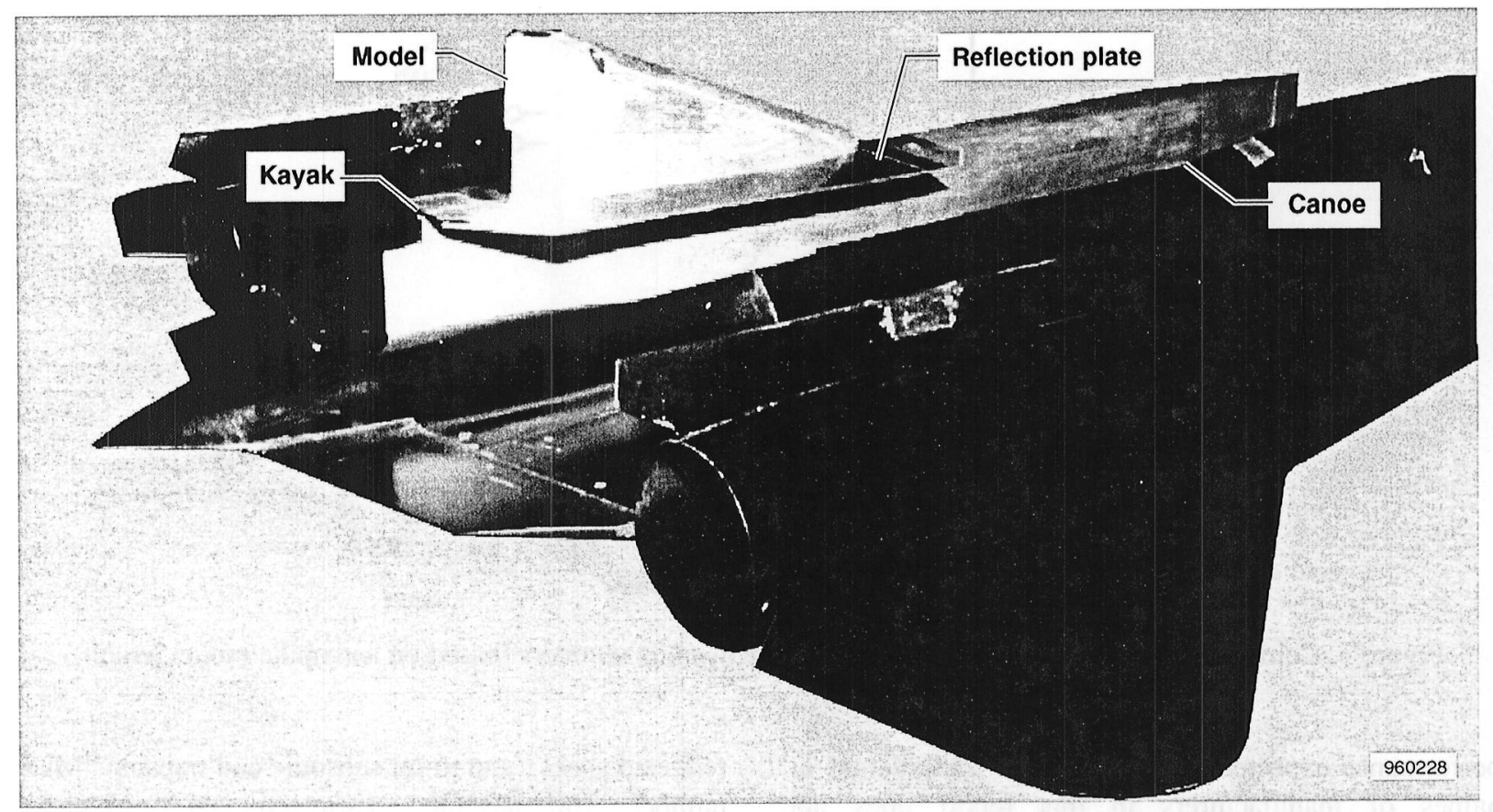

Figure 2. Aerospike pod wind-tunnel installation.

reflection plate is mounted on top of the kayak to promote uniform flow in the region of the model. Liquid oxygen and ignitor materials required to operate the engine are located in the model. The model is mounted vertically so that sideslip of the SR-71 airplane imparts angle of attack on the model. Unlike an actual X-33 configuration, the model has no camber so as not to produce side force when the SR-71 airplane is at $0^{\circ}$ sideslip. The desired Mach number and altitude ranges for the test extend to Mach 3.2 and an altitude of $84,000 \mathrm{ft}$ which are near the limits of the basic SR-71 flight envelope.

A series of wind-tunnel tests was conducted to support this flight project. The objectives were to define a LASRE configuration that could successfully be flown to the desired test points and to identify any aircraft envelope limitations. Principle areas of concern were transonic drag, supersonic stability, and control. Aerodynamic increments obtained in the wind tunnel represent the aerodynamic changes caused by the addition of the LASRE pod to the baseline SR-71 airplane.

The excess thrust available for the SR-71 airplane is minimal at transonic speeds. As a result, minimizing the transonic drag caused by the aerospike pod was necessary. The incremental drag obtained in windtunnel testing was incorporated into simulations of complete flight profiles. These simulations were done to determine if the configuration could meet the test objectives and to develop flight techniques for the transonic acceleration that would minimize fuel usage.

Stability and control issues investigated in the wind tunnel were primarily lateral-directional at takeoff and landing speeds and at the maximum Mach number. At low speeds, the cross-wind landing criterion with one engine not functioning needed to be satisfied with the aerospike pod configuration. At supersonic speeds, the SR-71 lateral-directional stability minimum occurs at Mach 3.2. Ensuring that the aerospike pod configuration does not significantly reduce the stability at Mach 3.2 was necessary. The incremental stability and control derivatives were added to the flight simulations to assess handling qualities and envelope restrictions caused by control surface authority limitations.

This report presents selected results from three windtunnel entries and flight simulation results based on wind-tunnel data. Potential flow analyses are also presented to help interpret the wind-tunnel results. The discussion of the results includes the unexpected nosedown pitching moment encountered with the first configuration tested and the solution to the pitching moment problem by altering the location of aerospike model; drag, stability, and control of various configurations; envelope limitations for the LASRE configuration; and maximum Mach number 


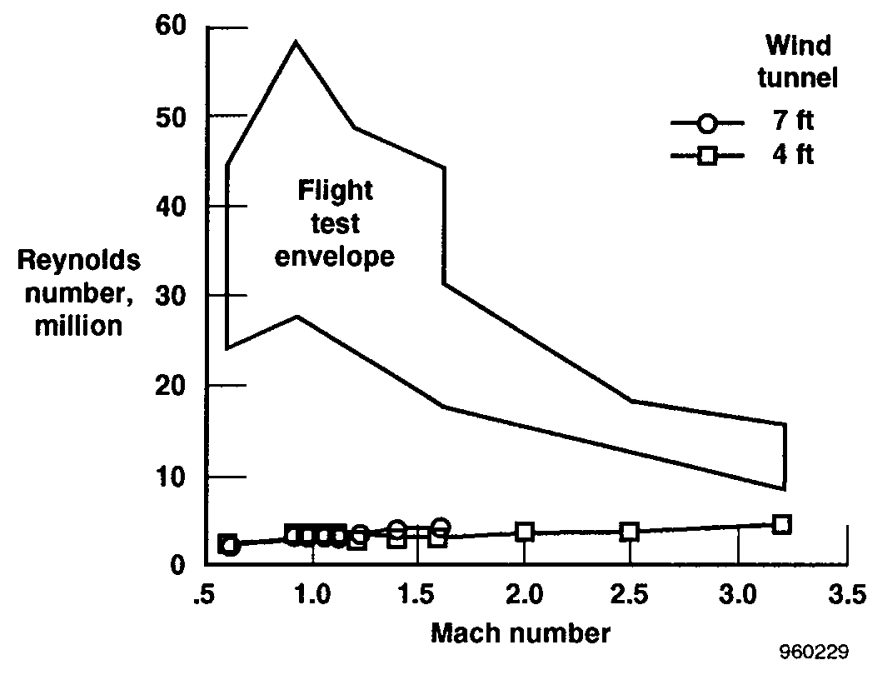

Figure 3. Comparison between wind tunnel and flight Reynolds numbers (based on aerospike model length).

performance expected in flight. Use of trade names or names of manufacturers in this report does not constitute an official endorsement of such products or manufacturers, either expressed or implied, by NASA

\section{Wind-Tunnel Facilities}

Two wind-tunnel facilities were used to test the LASRE configuration: the National Technical Systems (NTS) 4- $\times$ 4-ft blowdown wind tunnel in Saugus, California, ${ }^{9}$ and the MicroCraft $7-\times 7$-ft blowdown wind tunnel in El Segundo, California. ${ }^{* *}$ Minimum operating Reynolds numbers were adequate for these tests; therefore, these Reynolds numbers were used to conserve tank pressure and to maximize the time available for testing. Figure 3 shows a comparison of wind-tunnel and flight Reynolds numbers data. The model installation and test procedures for each facility are described next.

\section{NTS 4- $\times 4$-ft Blowdown Wind Tunnel}

The model was tested from Mach 0.6 to Mach 3.2. A transonic cart was inserted in the wind tunnel for testing at Mach 1.4 and below. The 22-percent porous walls of the transonic cart were actively suctioned to minimize

\footnotetext{
TWind Tunnel User's Manual, Kelly Johnson Research and Development Center at Rye Canyon, Lockhecd Acronautical Systems Company, Fluid Dynamics Laboratory, Junc 1990. [NTS; Ryc Canyon Research, Development, and Test Center; 25100 Rye Canyon Road; Building 202; Valencia, Califomia 91355, Telephone: (805) 259-8184, FAX: (805)257-3539]

*** Mennell, R.C., MicroCraft Trisonic Wind Tunnel User's Manual, NA-90-1484, MicroCraft, Inc., El Scgundo, California, Jan. 18, 1994. [MicroCraft, Inc., Trisonic Wind Tunnel; 400 Duley Rd.; El Segundo, California 90245, Telephone: (310) 335-1585, FAX: (310) 640-1056]
}

reflected shocks and to set subsonic and transonic Mach numbers. The transonic cart was removed for Mach 1.6 and above. Supersonic Mach number was controlled by contouring the upstream nozzle. At $8^{\circ}$ angle of attack, $\alpha$, wind-tunnel blockage was approximately 4.7 percent.

The model was supported with a sting mount entering the aft end of the fuselage. The force and moment balance was aligned with the fuselage reference plane of the model. Angle of attack was referenced to the wing reference plane which has an incidence angle of $-1.2^{\circ}$ with respect to the fuselage reference plane. A standard six-component balance was used for Mach 2.0 and below.

A five-component instrumented sting was specially fabricated and used from Mach 1.6 to Mach 3.2. The instrumented sting was necessary because the standard balance was not expected to be able to withstand the wind-tunnel start-up loads at the high Mach numbers. The five-component instrumented sting did not have an axial force measurement; therefore, lift and drag could not be computed.

The majority of the longitudinal aerodynamics data was obtained during angle-of-attack sweeps at $0^{\circ}$ sideslip. Some angle-of-attack sweeps were also done at $-5^{\circ}$ sideslip. Lateral-directional data were obtained during angle-of-sideslip sweeps with an angle of attack of $4^{\circ}$ (approximate cruise flight value).

\section{MicroCraft 7- $\times 7$-ft Blowdown Tunnel}

The model was tested from Mach 0.6 to Mach 1.6. All testing was done in the transonic section which had 19.7-percent porous walls. Mach number was controlled 
in the test section by adjusting the flexible nozzle, the downstream diffuser configuration, and a Mach number control flap which operated at $40 \mathrm{~Hz}$. At $8^{\circ}$ angle of attack, wind-tunnel blockage was approximately 1.5 percent.

The model was supported by a blade mount attached to the fuselage underside. A six-component balance was installed in the model to obtain the aerodynamic loads. Mach number was limited to Mach 1.6 because of windtunnel start-up loads on the balance. Angle-of-attack sweeps were used to obtain longitudinal data. Angle-ofattack sweeps at $-5^{\circ}$ sideslip were used to obtain lateral-directional data because angle-of-sideslip sweeps were not possible using the blade mount.

\section{Wind-Tunnel Models}

An existing 4-percent scale model of the SR-71 airplane was used for these tests. The main fuselage and wings were constructed of cast bronze. Aluminum was used for the forebody and tails. Flow through inlets were used for the model. The aft fuselage and inboard elevons were modified to accommodate the sting mount at the 4-ft tunnel. The true aft fuselage was used at the 7 - $\mathrm{ft}$ tunnel test in which the model was blade mounted. The vertical tails were manually positioned with brackets for $0^{\circ}, 5^{\circ}$, and $10^{\circ}$ rudder deflections. Separate inboard elevons were fabricated for $-10^{\circ}, 0^{\circ}$, and $10^{\circ}$ elevon deflections.

The aerospike pod consisted of a canoe, reflection plate, model, and, in some cases, a kayak (fig. 2). The pod was tested in various locations on the SR-71 airplane. The two primary configurations were referred to as the forward model and aft model (figs. 4 and 5). The majority of the pod components were fabricated of aluminum. The lone exception is the reflection plate which was fabricated of stainless steel. Two canoes were used. The first canoe was used with the forward model configuration, and the slightly longer second canoe was used with the aft model configuration. Use of the kayak was limited to the aft model configuration. Grit strips were used on the pod to create a turbulent boundary layer over the pod components at approximately 5 -percent chord. The grit grain was sized to 0.0034 in. for all tests.

\section{Wind-Tunnel Testing}

Table 1 summarizes the wind-tunnel test sequence. The first wind-tunnel entry occurred at the NTS 4- $\times 4-\mathrm{ft}$ tunnel. The initial LASRE configuration tested was the forward model configuration (fig. 4). After testing numerous configurations, the final configuration tested was an initial aft model configuration. Because of the limited amount of wind-tunnel time remaining, only a partial set of aerodynamic data was obtained for this configuration. Before the second wind-tunnel entry, the aft model configuration was modified slightly by extending the length of the canoe and adding the section known as the kayak to incline the reflection plate $2^{\circ}$ nosedown (fig. 5).

The second wind-tunnel entry occurred at the MicroCraft $7-\times 7$ - $\mathrm{ft}$ wind tunnel because it could accommodate a blade mount. The blade mount was necessary because testing the configuration with the true SR-71 aft fuselage was desired. Testing was primarily on the aft model configuration from Mach 0.6 to

Table 1. Wind-tunnel test summary.

\begin{tabular}{|c|c|c|c|c|c|}
\hline Entry & Facility & Mount & Balance & $\begin{array}{l}\text { Mach } \\
\text { number }\end{array}$ & Objectives \\
\hline \multirow[t]{2}{*}{1} & \multirow[t]{2}{*}{ NTS } & \multirow[t]{2}{*}{ Sting } & Six component & $0.6-2.0$ & $\begin{array}{l}\text { Transonic drag } \\
\text { Stability } \\
\text { Rudder effectiveness }\end{array}$ \\
\hline & & & Five component & $2.5-3.2$ & $\begin{array}{l}\text { Stability } \\
\text { Rudder effectiveness }\end{array}$ \\
\hline 2 & MicroCraft & Blade & Six component & $0.6-1.6$ & $\begin{array}{l}\text { Transonic drag } \\
\text { Stability } \\
\text { Rudder effectiveness } \\
\text { Elevon effectiveness }\end{array}$ \\
\hline 3 & NTS & Sting & Five component & $1.6-3.2$ & $\begin{array}{l}\text { Stability } \\
\text { Rudder effectiveness } \\
\text { Elevon effectiveness }\end{array}$ \\
\hline
\end{tabular}



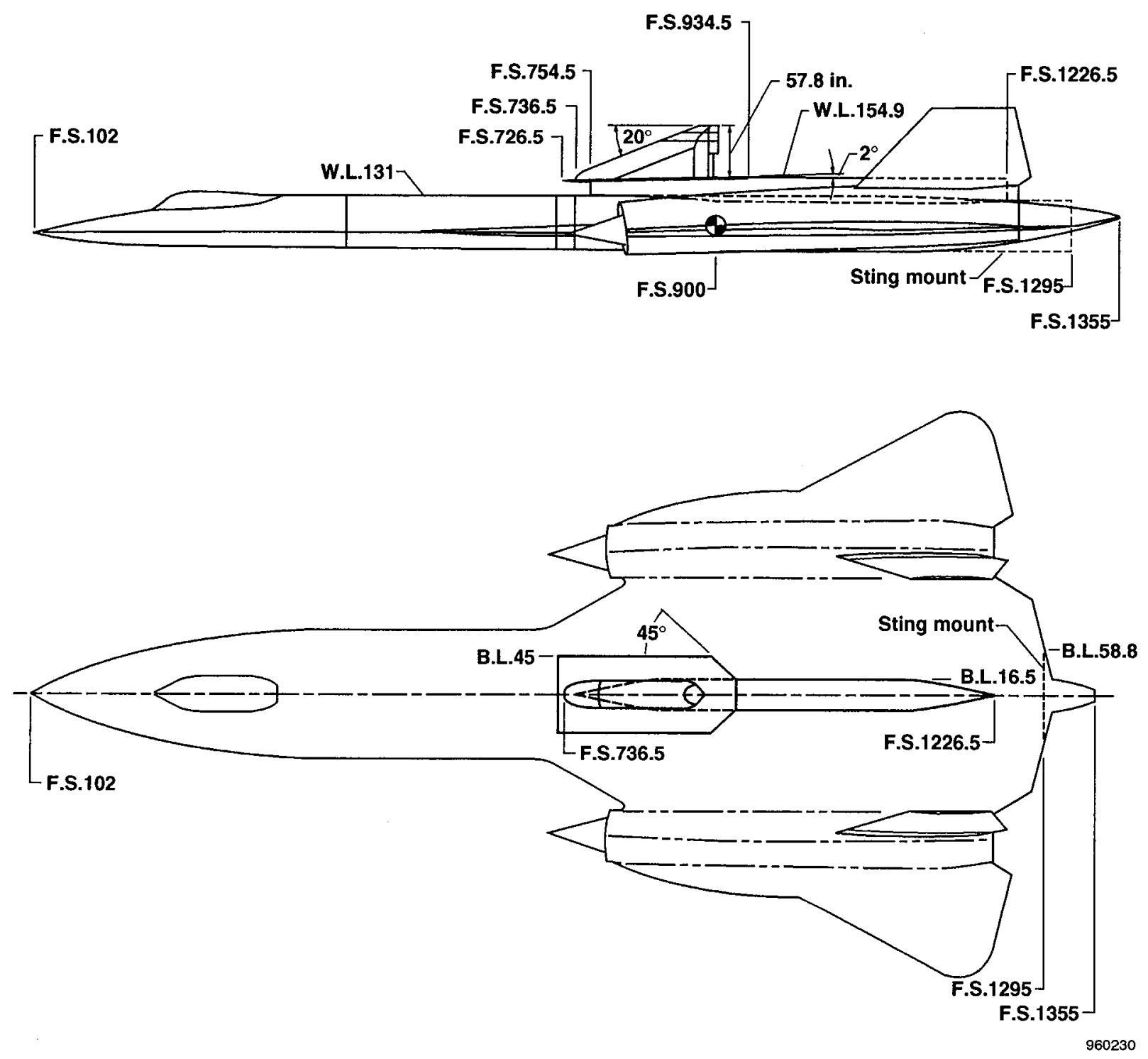

Figure 4. LASRE forward model configuration.

Mach 1.6. Data were also obtained for the forward model configuration at Mach 1.1 with the modified and true SR-71 aft fuselages. For this entry, elevon effectiveness was also tested.

The final entry occurred at the NTS $4-\times 4$-ft wind tunnel. The instrumented sting was used for testing the aft model configuration from Mach 1.6 to Mach 3.2. The standard balance was not used for Mach 2.0 and below to save wind tunnel set up time. In addition, drag was not a required measurement for these tests. Elevon effectiveness was again tested with special elevons fabricated to accommodate the sting mount.

\section{Aerodynamic Model}

Aerodynamic data for the baseline SR-71 and LASRE configurations were obtained in these wind-tunnel tests. Increments in the aerodynamic coefficients and derivatives were calculated by subtracting the windtunnel baseline SR-71 data from the wind-tunnel data for the LASRE configuration. These increments were then added to the baseline SR-71 rigid body aerodynamic model $^{3}$ to obtain the LASRE aerodynamic model. This model was then used in the simulations for performance, stability and control, handling qualities analysis, mission planning, and crew training. 

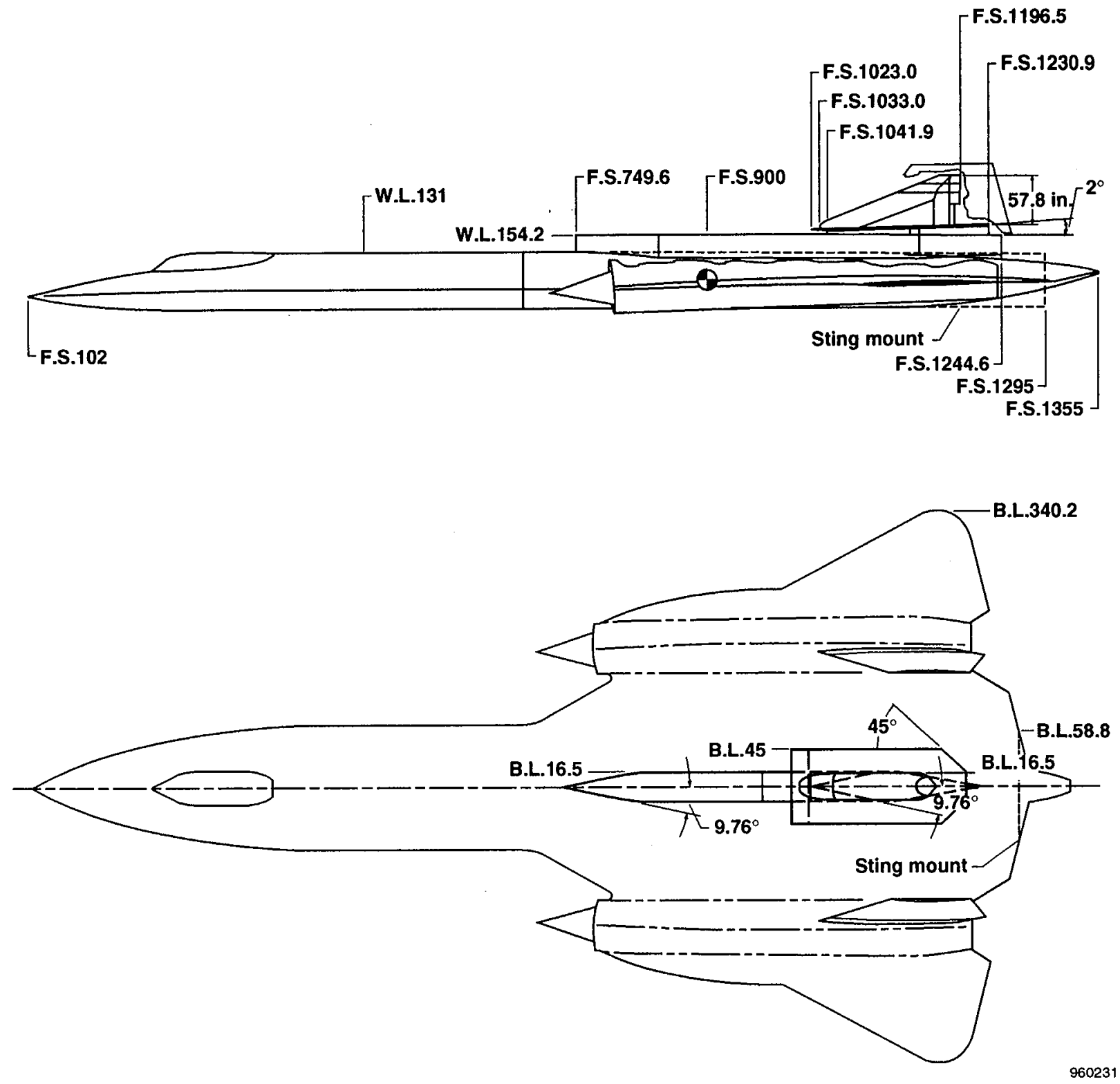

Figure 5. LASRE aft model configuration.

Flexibility corrections to the rigid body aerodynamics of the baseline SR-71 airplane are documented in reference 3 and included in the simulation. No attempt was made to identify the flexibility corrections caused by the addition of the LASRE pod. The force and moment equations used in the simulations are shown below with the inclusion of the increments measured during wind-tunnel testing. The form of these equations was determined as a result of the wind-tunnel testing. The only increments included in the aerodynamic model were those needed to adequately represent the LASRE configuration aerodynamics. Some of these increments are a function of Mach number; whereas, others are a function of Mach number and angle of attack.

$$
\begin{aligned}
& C_{L}=C_{L_{\text {Baseline }}}+\Delta C_{L}(M, \alpha) \\
& C_{D}=C_{D_{\text {Baseline }}}+\Delta C_{D}(M, \alpha) \\
& C_{m}=C_{m_{\text {Baseline }}}+\Delta C_{m}(M, \alpha)+\Delta C_{m_{\delta e}}(M) \delta e
\end{aligned}
$$




$$
\begin{gathered}
C_{Y}=C_{Y_{\text {Baseline }}}+\Delta C_{Y_{\beta}}(M, \alpha) \beta+\Delta C_{Y_{\delta r}}(M) \delta r \\
C_{l}=C_{l_{\text {Baseline }}}+\Delta C_{l_{\beta}}(M, \alpha) \beta+\Delta C_{l_{\delta r}}(M) \delta r \\
C_{n}=C_{n_{\text {Baseline }}}+\Delta C_{n_{\beta}}(M, \alpha) \beta+\Delta C_{n_{\delta r}}(M) \delta r
\end{gathered}
$$

The reference area for the SR-71 airplane is $1605 \mathrm{ft}^{2}$, the reference chord is $37.7 \mathrm{ft}$, and the reference span is $56.7 \mathrm{ft}$. The moment reference is located at fuselage station (F.S.) 900, waterline (W.L.) 100, and butt line (B.L.) 0 .

\section{Wind-Tunnel Comparisons}

A limited number of data comparisons between the two wind-tunnels was made. Of particular interest were the transonic results because reflected shocks and tunnel blockage in these small wind tunnels were a concern. Figure 6 shows comparisons for the aft model configuration. The transonic data in the 7-ft tunnel were taken with the final aft model configuration. The transonic data in the 4-ft tunnel came from the first wind tunnel entry before the final configuration was established. The configuration used in the 4- $\mathrm{ft}$ tunnel test did not include the kayak, and the reflection plate was not inclined $2^{\circ}$. The reflection plate was raised approximately $3 / 16$ in. at three post locations. In addition, the length of the canoe was slightly shorter in the 4- $\mathrm{ft}$ tunnel test. The aerodynamic effect of these differences was assumed to be minor.

The untrimmed drag data showed excellent agreement between the two tunnels for supersonic Mach numbers (fig. 6(a)). The 7-ft wind tunnel showed significantly larger drag increments for Mach 0.9 and Mach 0.95 than the 4- $\mathrm{ft}$ wind tunnel. The reason for this difference is unknown. Because blockage was low for the 7 -ft tunnel and these results were conservative, the drag increments from this $7-\mathrm{ft}$ tunnel were used in the subsequent performance studies. Figure 6(b) shows the pitching moment increments at $4^{\circ}$ angle of attack for the two wind tunnels. The shapes of these curves agree well as seen in the peak nosedown pitching moment at Mach 0.9 and the peak nose-up pitching moment at Mach 1.05 .

\section{Wind-Tunnel Measurement Accuracies}

The expected accuracies of the internal sixcomponent balances used were 0.25 percent of applied load. The expected accuracy of the five-component instrumented sting was 1 percent of applied load. Good repeatability of these data within this accuracy was demonstrated at the 7-ft tunnel. Repeatability was not as good at the 4-ft tunnel when comparisons were made of runs from different days.

On the other hand, good repeatability was obtained in the 4-ft tunnel for data runs that occurred during same day testing. In terms of force and moment accuracies at this wind tunnel, the worst repeatabilities resulted in $\Delta C_{m}$ differences of $0.006, \Delta C_{L}$ differences of 0.03 , and $\Delta C_{D}$ differences of 0.0025 . The force and moment balance results presented here are more nearly accurate than these quoted differences because wherever possible increments were obtained from same day testing.

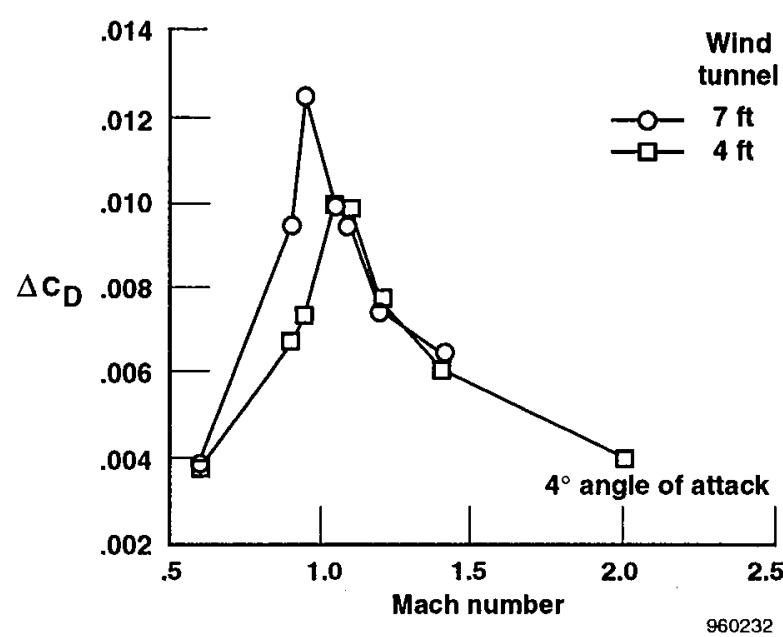

(a) Untrimmed drag increment.

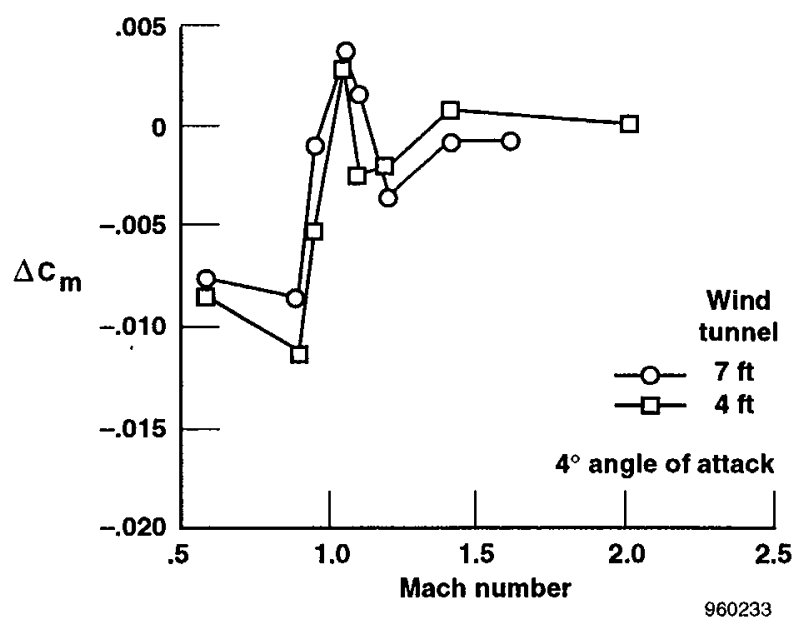

(b) Pitching moment increment.

Figure 6. Comparisons of data from the 4- and 7-ft wind tunnels for the LASRE aft model configuration. 
The majority of the flow angle accuracies were well within $0.2^{\circ}$. The 7 - $\mathrm{ft}$ tunnel flow angle data were expected to be within $0.1^{\circ}$ because there was not much deflection of the blade mount. On the other hand, some "slop" in the installation was attributed to an unknown error of $\pm 0.05^{\circ}$. For the sting-mounted tests at the 4-ft tunnel, additional uncertainty existed because of fairly large sting deflections.

\section{Potential Flow Computer Tools}

A computational analysis of the LASRE configuration was conducted to validate the wind-tunnel results and to allow diagnosis of the aerodynamic phenomenon associated with many of the LASRE configurations tested. The two codes used in this study are commonly known as A502 ${ }^{4}$ and TranAir. ${ }^{5,6}$ The A502 code, a linear potential (Prandtl-Glauret) flow solver, was run on a workstation and is useful for subsonic and supersonic flows but not for transonic. TranAir is a finite-element, full-potential flow solver and can, therefore, be run at transonic Mach numbers. TranAir was run on a Cray C-90 (Cray Research, Inc., Minneapolis, Minnesota) computer at the NASA Ames Research Center, Moffett Field, California. The input grid for A502 and TranAir is identical.

\section{Flight Simulation}

Flight simulations using the LASRE aerodynamic database were integral to developing the final configuration. These simulations assessed performance, stability and control, and handling qualities associated with the various configurations. Flight simulations were conducted concurrently with wind-tunnel testing, and the results were used to modify the wind-tunnel test plan.

Three simulations were used at DFRC during development of the LASRE configuration. These simulations are referred to as the batch sim, performance sim, and real-time sim. The batch sim was run on a workstation for a prescribed flight trajectory. Outputs from the batch sim were used for stability and control, handling qualities, operational limits, and performance analyses. The trimmed drag outputs from the prescribed trajectory were the primary input to the performance sim. The performance sim was also run on a workstation and was used to assess transonic and maximum Mach number performance of the LASRE configuration. The real-time sim is a full-cockpit, piloted simulation in which project pilots could develop flight trajectories and assess handling qualities. Developing a flight trajectory that would minimize the fuel use during the acceleration through the transonic Mach numbers and, therefore, maximize the final Mach number attainable for testing was of particular interest.

\section{Results and Discussion}

This section presents representative wind-tunnel results and some comparisons with potential flow results. The forward model configuration is discussed first because it was the initial LASRE configuration. This configuration was unacceptable because of an excessive amount of nosedown pitching moment at transonic speeds. Numerous configuration investigations revealed that the aft model configuration was acceptable. A discussion of the aerodynamics associated with the aft model configuration is followed by a description of the causes of the nosedown pitching moment. This section concludes with the ramifications of the aerospike pod on SR-71 performance and control.

\section{Forward Model Configuration}

Figure 4 shows the forward model configuration. Before wind-tunnel testing, this configuration was the baseline for the LASRE project because of center of gravity (c.g.) and flow quality considerations. The aerodynamic model increments obtained for the forward model configuration are tabulated in appendix $\mathrm{A}$.

Longitudinal aerodynamic increments are tabulated in tables A-1, A-2, and A-3. Trim angle of attack for the SR-71 airplane is roughly $4^{\circ}$ for the majority of the flight Mach numbers. Figure 7 shows the untrimmed drag and pitching moment increment curves for $4^{\circ}$ angle

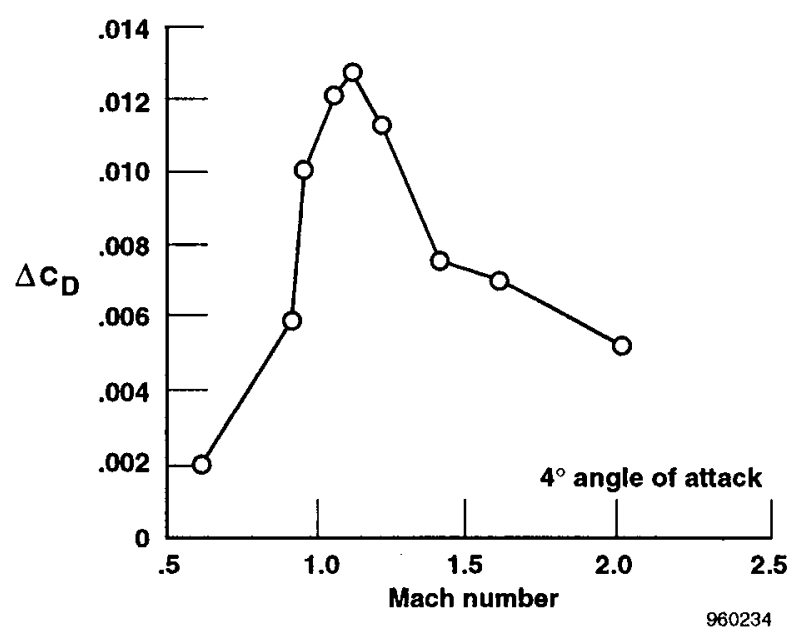

(a) Untrimmed drag increment.

Figure 7. Aerodynamic increments caused by the aerospike pod with the model in the forward position. 


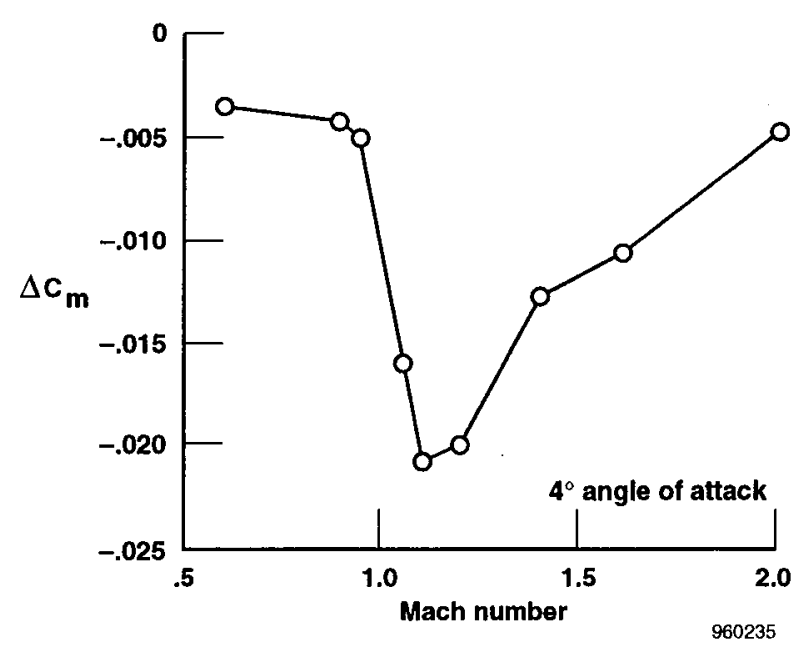

(b) Pitching moment increment.

Figure 7. Concluded.

of attack. These data were obtained in the 4-ft wind tunnel. The peaks in the drag and pitching moment occur at Mach 1.1. For $4^{\circ}$ angle of attack, the maximum untrimmed drag increment is $128 \mathrm{drag}$ counts (fig. 7(a)), and the maximum nosedown pitching moment increment is 0.0208 (fig. 7(b)). This amount of nosedown pitching moment is excessive, and the cause is discussed in the Nosedown Pitching Moment subsection.

Figure 8 shows the trim drag penalty associated with the forward model configuration. The flight simulators showed that the combined pod and trim drag increment was greatly in excess of the power available for acceleration through the transonic Mach numbers.

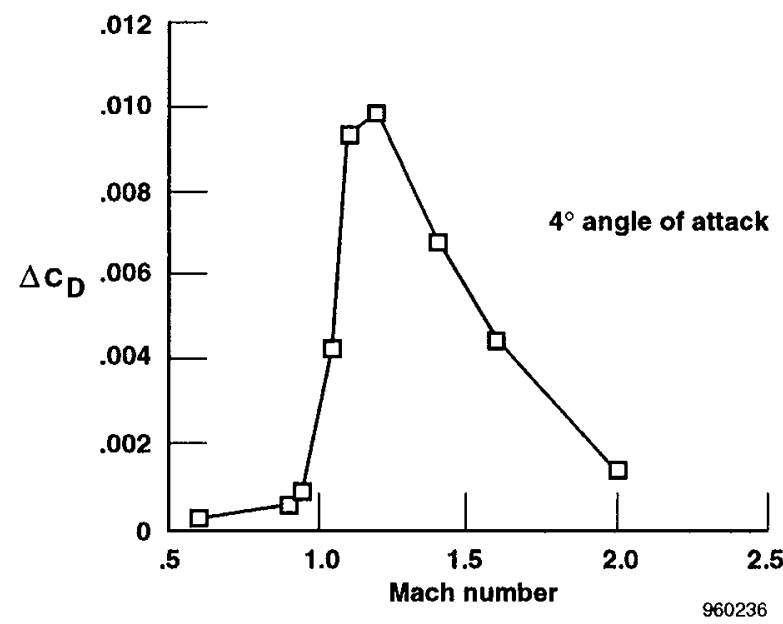

Figure 8 . Trim drag increment caused by the aerospike pod with the model in the forward position.
Hinge moment analysis also showed that there was not enough actuator control power for trim.

Lateral-directional stability of the forward model configuration was investigated in the 4 - $\mathrm{ft}$ tunnel. The model was swept through $\pm 8^{\circ}$ angle of sideslip with the angle of attack set to a value near the expected trim angle of $4^{\circ}$. Data were obtained at four Mach numbers (table A-4).

Figure 9 shows the yawing and rolling moment sideslip derivatives for the baseline SR-71 airplane and the forward model LASRE configuration. The $C_{n_{\beta}}$ is significantly reduced for the LASRE configuration and rapidly approached instability as the Mach number increased. This configuration would have resulted in the LASRE being limited to a maximum of approximately Mach 1.9 because of decreased directional stability. The rolling moment derivative, $C_{l_{\beta}}$, demonstrated an unexpected decrease in rolling stability. It was thought that this derivative would become more negative because of the large lifting body above the SR-71 centerline.

\section{Aft Model Configuration}

Figure 5 shows the aft model configuration. The complete set of aerodynamic model increments
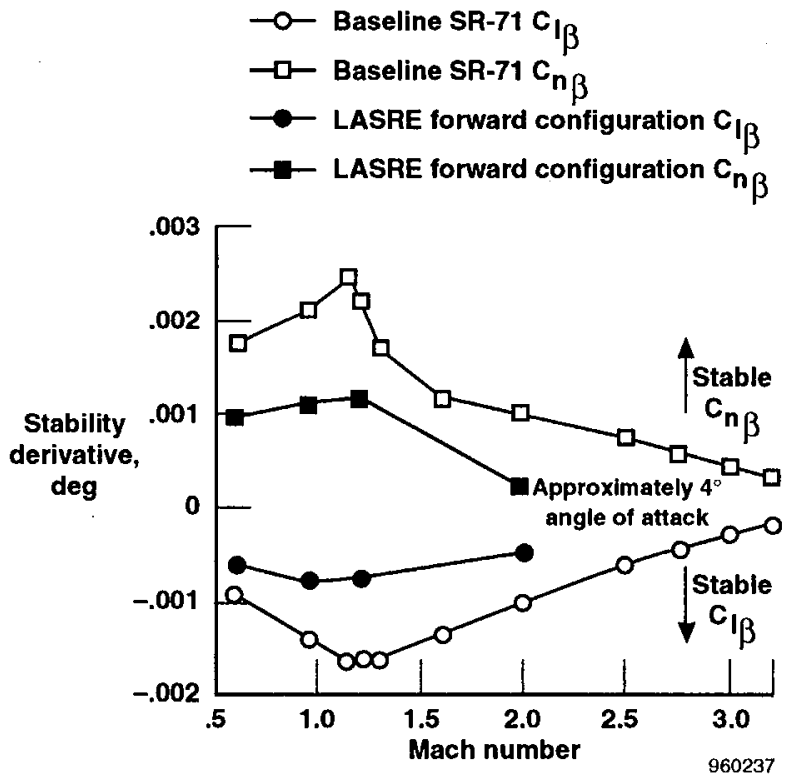

Figure 9. Yawing and rolling moment sideslip derivatives for the baseline SR-71 airplane and the LASRE forward model configuration. 
measured for the aft model configuration is tabulated in appendix B. During the first wind-tunnel test at the $4-\mathrm{ft}$ tunnel, an initial aft-mounted model configuration was tested which did not include the kayak or the $2^{\circ}$ nosedown incidence. In addition, the reflection plate was raised approximately $3 / 16$ in. above the canoe.

Figure 10 shows a drag and pitching moment comparison between the forward- and aft-mounted configurations. Moving the model aft changed the

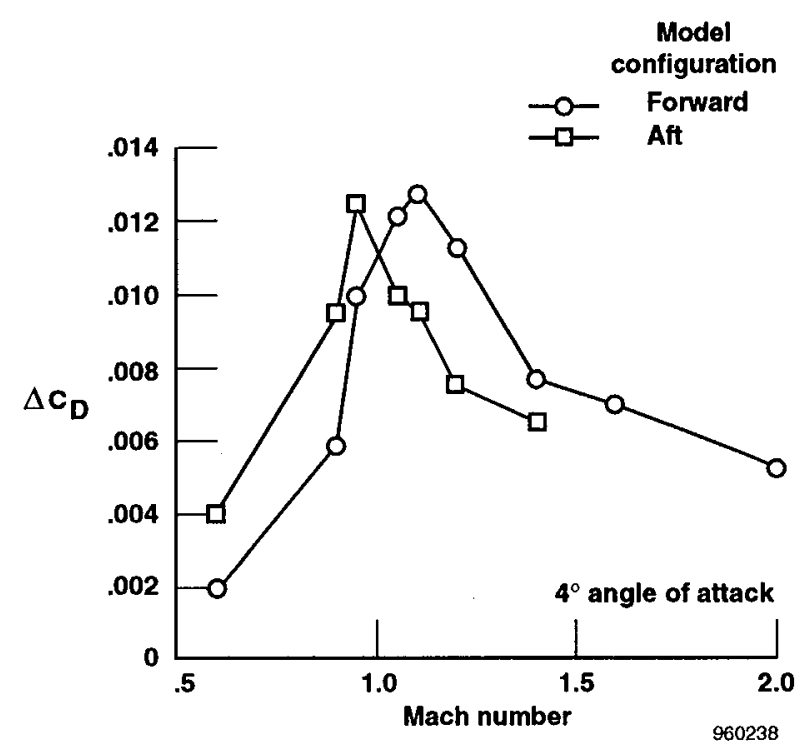

(a) Untrimmed drag increments.

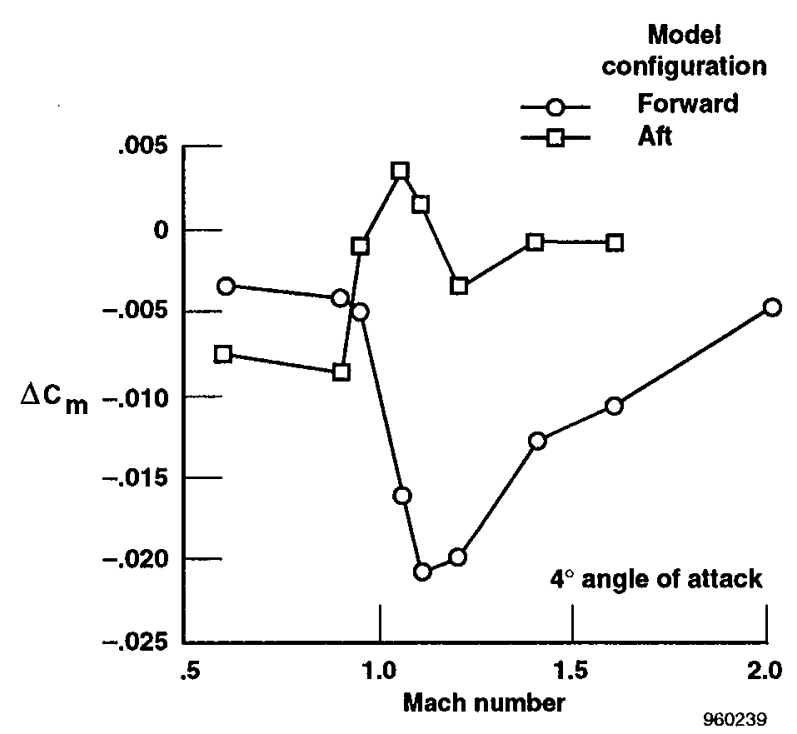

(b) Pitching moment increments.

Figure 10. Comparison of aerodynamic increments caused by the aerospike pod with the model in the forward and aft positions. untrimmed drag peak from Mach 1.1 to Mach 0.95 (fig. 10(a)). For all supersonic Mach numbers, the untrimmed drag increment at $4^{\circ}$ angle of attack was smaller for the aft model configuration. The large improvement obtained in the pitching moment increment was more important than the drag. Above Mach 0.9, the pitching moment increment was much closer to zero with the aft model (fig. 10(b)). A somewhat increased nosedown pitching moment was measured for Mach 0.6 and Mach 0.9.

As in the forward model configuration, the drag and pitching moment increments for the aft model were incorporated into the batch simulator to come up with trimmed drag estimates for a nominal LASRE flight and c.g. profile. Figure 11 shows the trimmed drag estimates for the forward and aft model configurations. The increased drag increments at Mach 0.9 and Mach 0.95 initially were a concern; however, studies in the performance simulator showed that the affect of these increased drag increments was not of major significance because of sufficient excess thrust of the SR-71 airplane in this Mach number range.

\section{Nosedown Pitching Moment}

The large nosedown pitching moment associated with the forward model configuration was unexpected. The primary effect of the pod was expected to be a drag component acting above the centerline which would produce a nose-up pitching moment. A literature review subsequently revealed that this nosedown phenomenon

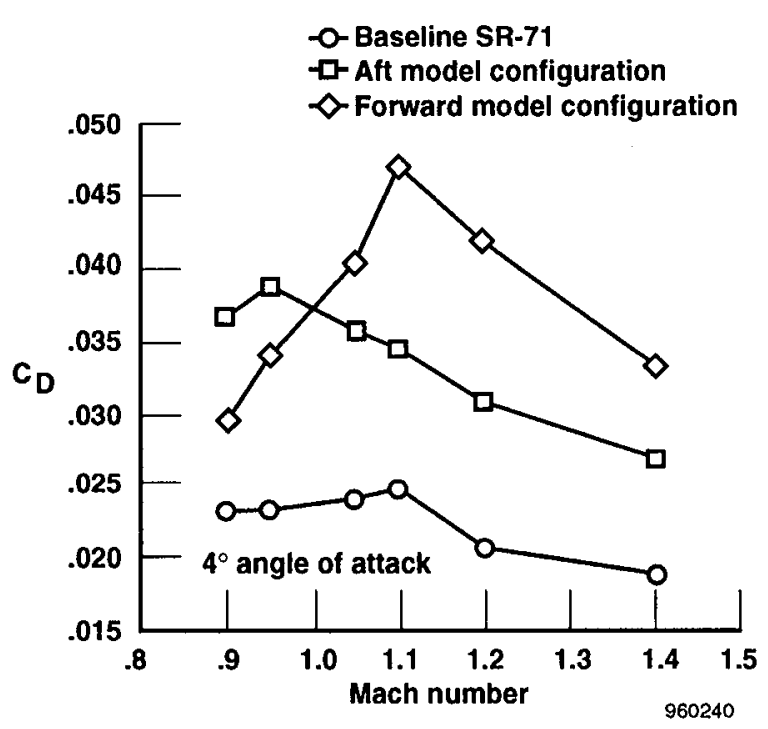

Figure 11. Trimmed drag comparison between forward and aft model configurations. 
was not without precedent. A search of the LockheedMartin archives uncovered a wind-tunnel test in which a top-mounted payload caused a similarly large nosedown pitching moment. ${ }^{7}$

Because trim drag is a key performance issue in the design, an effort was made to understand the causes of the nosedown pitching moment. A component buildup of the configuration and an investigation into the aft fuselage effects were conducted in the wind tunnel. Potential flow analyses were also done to help understand this phenomenon.

\section{Component Buildup}

The additive pitching moment effects of the individual components of the forward model configuration were measured at Mach 1.1 and Mach 1.6 in the 4-ft tunnel. The component buildup consisted of the baseline SR-71 airplane and then individually adding the canoe, reflection plate, and model. For Mach 1.1, the addition of the canoe alone was responsible for the majority of the negative $C_{m_{0}}$ shift (fig. 12).

The team speculated that for supersonic Mach numbers, the shock on the bow of the canoe caused a high-pressure region forward of the moment reference (F.S. 900). In addition, expansion fans on the aft end of the canoe caused a low-pressure region far aft of the moment reference. Both of these effects would contribute to a nosedown pitching moment. The addition of the reflection plate had minimal affect on the pitching moment. The addition of the model increased

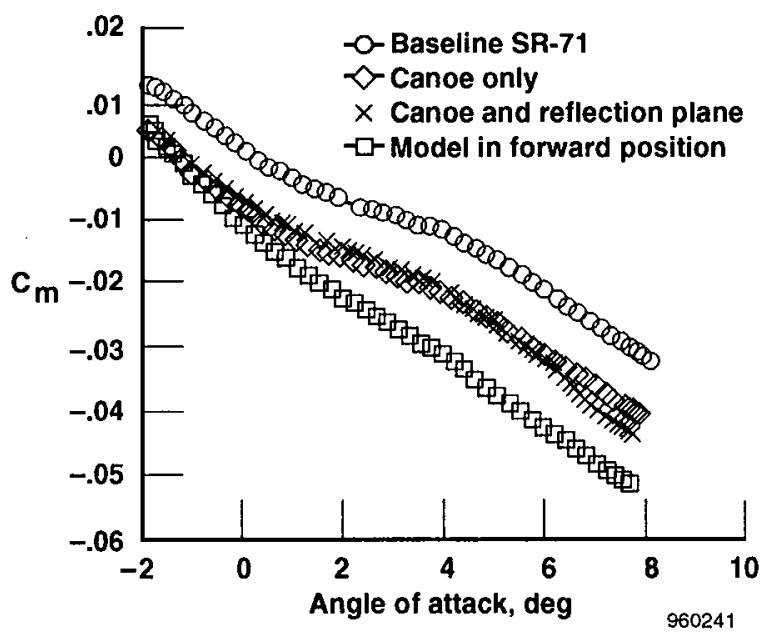

Figure 12. Pitching moment coefficient for the forward model configuration component buildup at Mach 1.1 in the 4 - $\mathrm{ft}$ wind tunnel. the nosedown pitching moment for angles of attack greater than $0^{\circ}$. For angles of attack greater than $3^{\circ}$, onehalf of the nosedown pitching moment was caused by the canoe, and one-half was caused by the model. Similar results were shown in the component buildup at Mach 1.6 (fig. 13). At Mach 1.6, the model added a $C_{m_{0}}$ approximately equal to that of the canoe.

\section{Aft Fuselage Effects}

For the first wind-tunnel test, the aft fuselage of the SR-71 airplane was modified to accommodate the sting installation. Uncertainty existed as to whether or not the modification contributed to the large nosedown pitching moment. The second wind-tunnel test provided an opportunity to determine if there was an effect because the model was blade-mounted and had the true aft fuselage. The baseline SR-71 airplane and forward model configurations were tested with the actual and modified SR-71 aft fuselages.

Figure 14 shows the results for Mach 1.1. Figure 14(a) shows the pitching moment as a function of angle of attack, and figure 14(b) shows the pitching moment increments. The aft fuselage modification did not significantly affect the nosedown pitching moment increment at any angle of attack (fig. 14(b)).

\section{Potential Flow Analysis}

TranAir analyses were done at Mach 1.1 to assess the influence of the canoe and the SR-71 aft fuselage on the pitching moment. In the component buildup phase of the wind-tunnel test, results were obtained for the

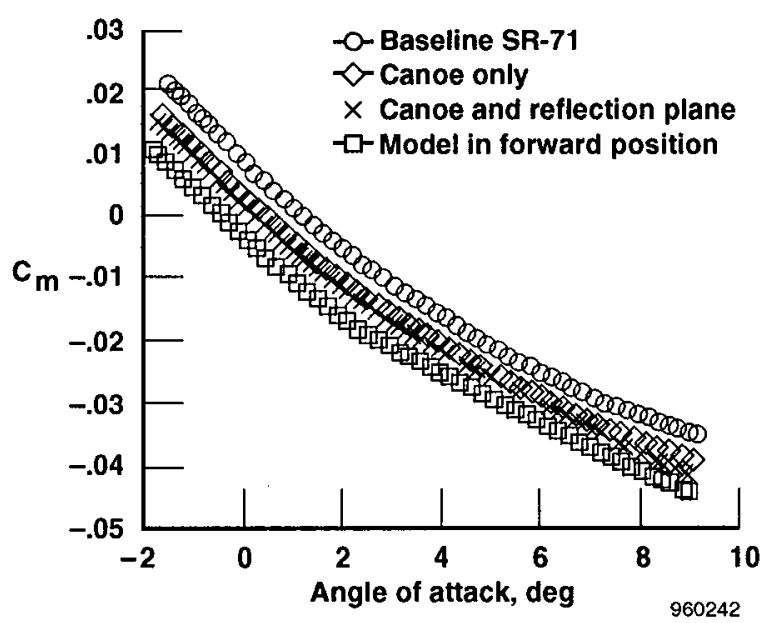

Figure 13. Pitching moment coefficient for the forward model configuration component buildup at Mach 1.6 in the 4 - $\mathrm{ft}$ wind tunnel. 


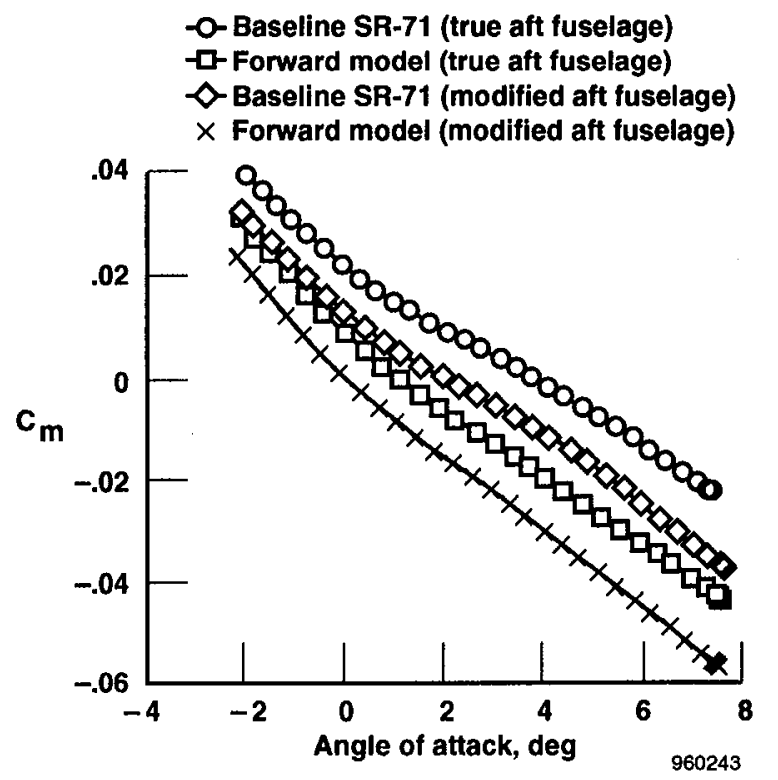

(a) Pitching moments.

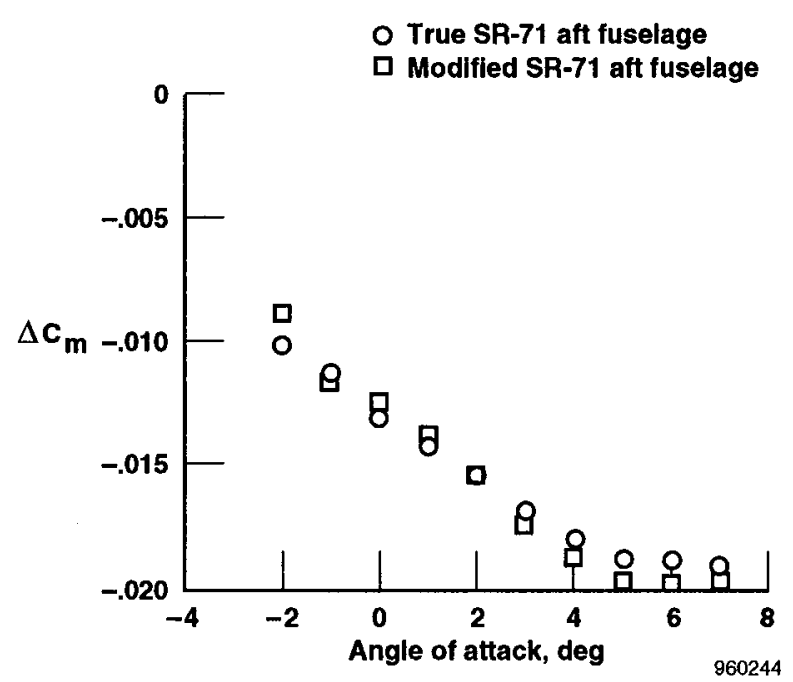

(b) Pitching moment increments.

Figure 14. Comparison of pitching moment effects caused by the true SR-71 aft fuselage and the modified aft fuselage for the forward model configuration (Mach 1.1, 7-ft wind tunnel).

canoe-only configuration with the SR-71 aft fuselage modified for the sting mount.

Figure 15 shows pitching moment increments caused by the canoe from TranAir and the wind tunnel. The TranAir increments agree well with the wind-tunnel data. In addition, TranAir validated that the SR-71 aft fuselage configuration had no major affect on the pitching moment increment.

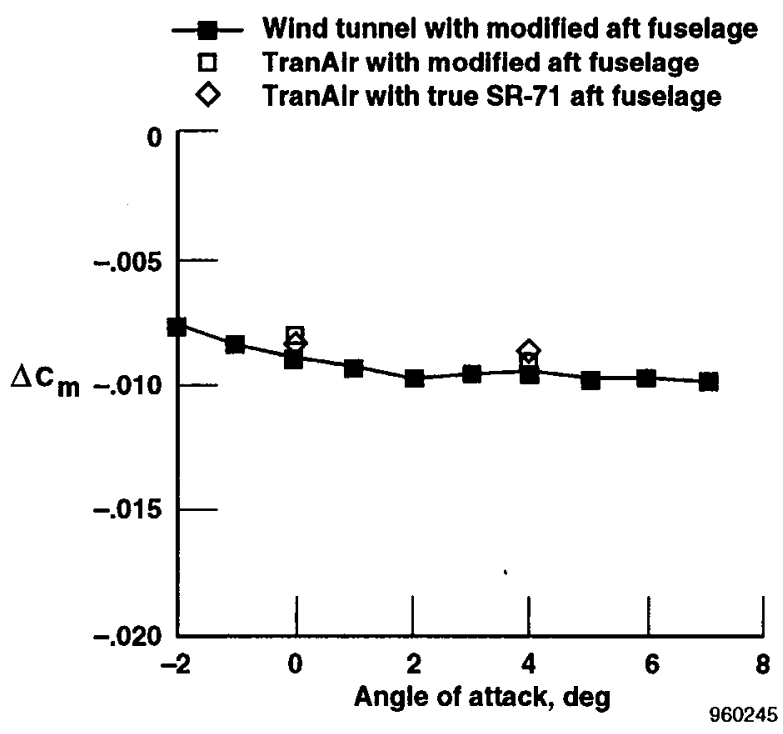

Figure 15. Comparison of TranAir and wind-tunnel results for the canoe-only configuration at Mach 1.1.

Figure 16 displays TranAir surface pressures for the baseline SR-71 airplane and canoe-only configurations at $4^{\circ}$ angle of attack. A high-pressure region exists forward of the canoe, and a low-pressure region exists aft of the canoe as compared to the baseline SR-71 airplane (figs. 16(a) and 16(b)).

These pressures can also be seen in the fuselage surface pressure distribution for B.L. 19.4 (which is slightly outboard of the canoe outer wall at B.L. 15.0) (fig. 17). Recalling that the moment reference is at F.S. 900 easily clarifies how the canoe alone can cause a nosedown pitching moment. A shock is formed off the bow of the canoe, pressurizing the SR-71 fuselage forward of the canoe. In addition, an expansion fan is extended at the end of the canoe, lowering the pressure on the fuselage.

Unlike the supersonic data, wind-tunnel results (fig. 10(b)) showed that subsonically the aft model configuration had a larger nosedown pitching moment increment than the forward model configuration. To identify the reason for this, A502 code analyses were completed at Mach 0.6 for the baseline SR-71 airplane, canoe-only, forward model, and aft model configurations. For the forward configuration, the A502 code predicted a pitching moment increment of -0.0018 ; whereas, the wind-tunnel increment was -0.0034 . For the aft model configuration, A502 code predicted an increment of -0.0076 ; whereas, the windtunnel increment was -0.0084 . Hence, A502 code concurred that the pitching moment became increasingly negative as the model was moved aft. 

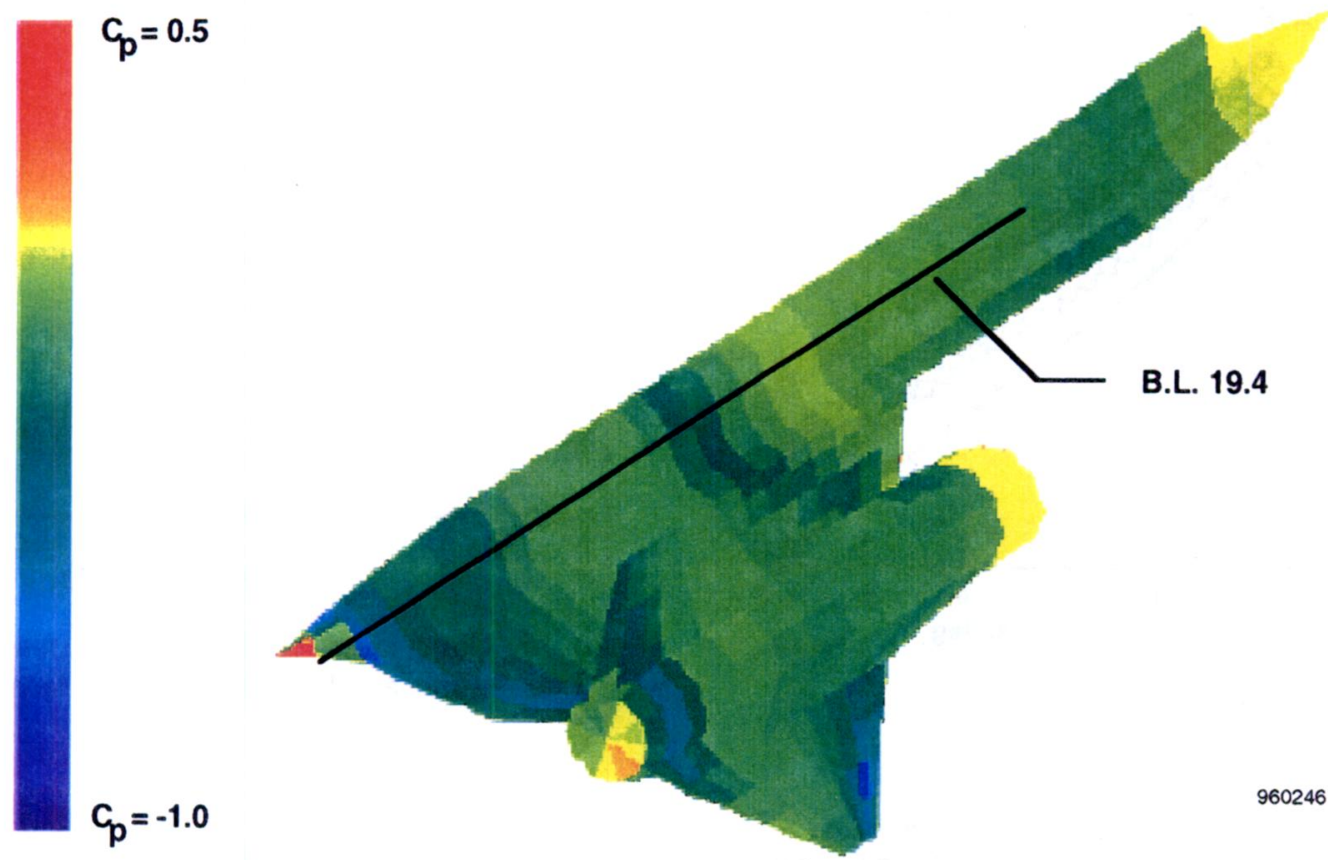

(a) Baseline SR-71 airplane.

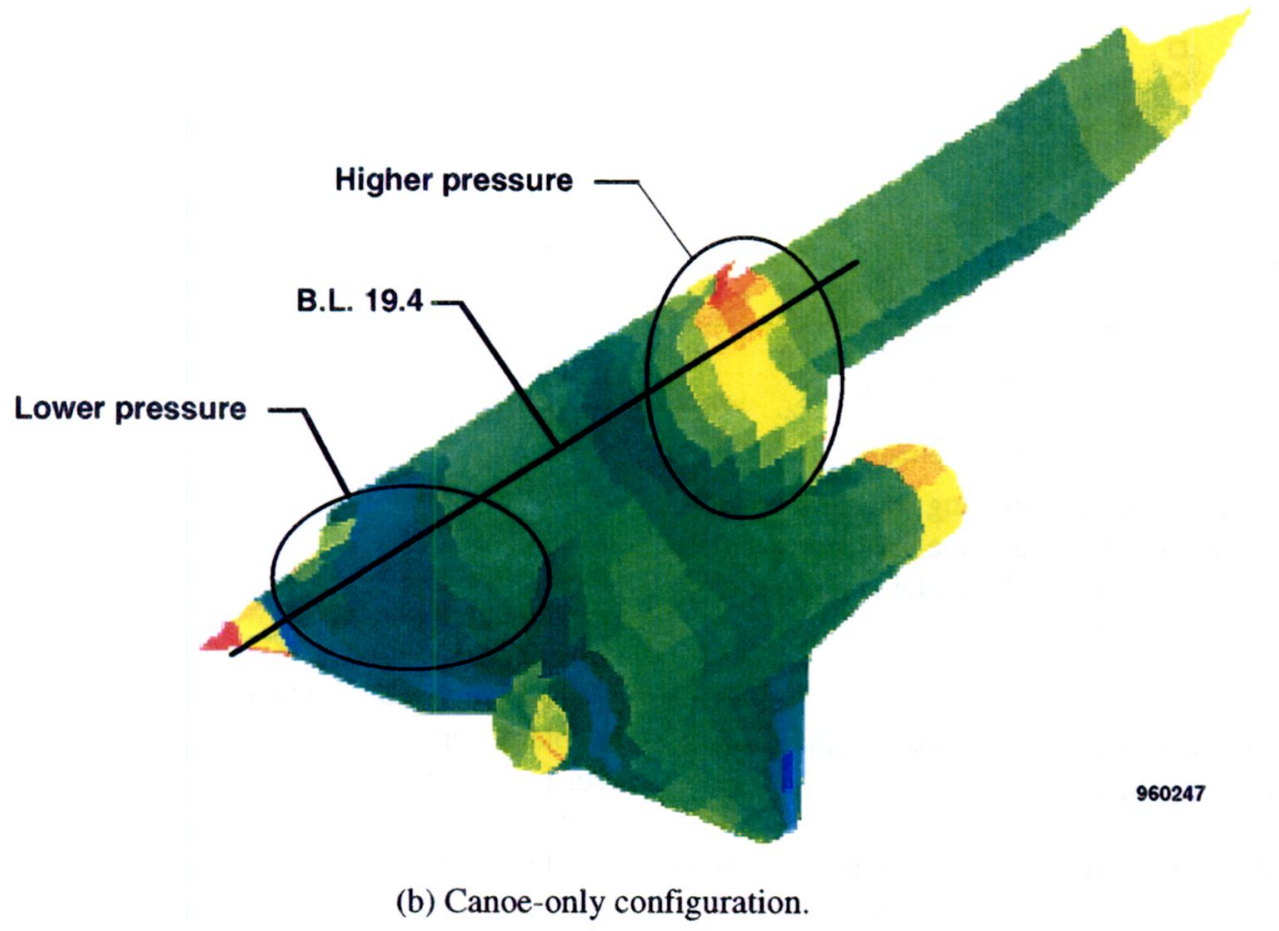

Figure 16. TranAir surface pressure maps at Mach 1.1 and $4^{\circ}$ angle of attack. 


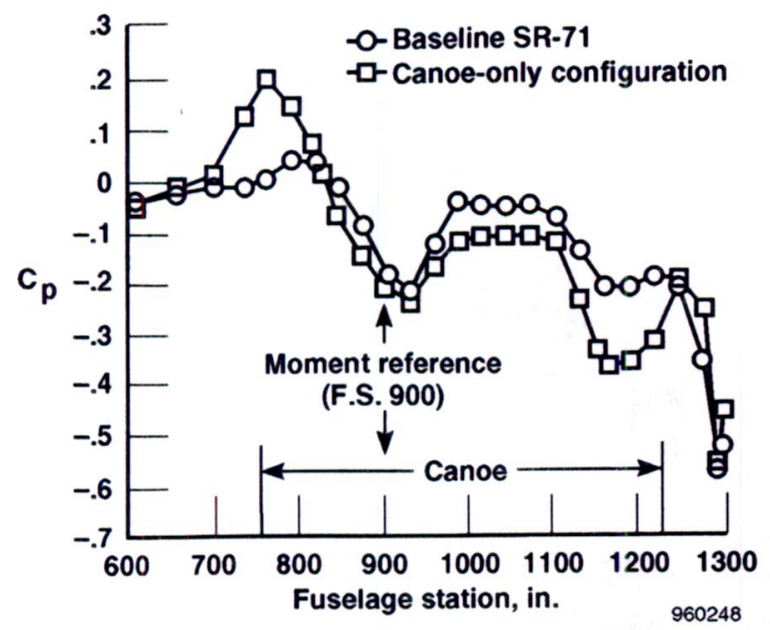

Figure 17. TranAir pressure distributions at B.L. 19.4 for the canoe-only configuration at Mach 1.1 and $4^{\circ}$ angle of attack.

The baseline SR-71 airplane, canoe-only, forward model, and aft model configuration pressure maps are shown in figures 18(a) through 18(d). Figure 19 shows the chordwise pressure distributions for the 22-percent semispan wing station. Note that for the canoe-only configuration, comparing figures 18 (a) with figure 18(b) and from figure 19 reveals a slightly increased pressure region forward of the canoe. More significantly, a decreased pressure region extends from the canoe to the wing at the location where the canoe width starts to decrease. The combination of these effects would cause a nosedown pitching moment for the canoe-only configuration. The A502 code predicted a pitching moment increment of -0.0032 for the canoe-only configuration.

With the model installed, low-pressure regions are seen on the leading edge of the aerospike model and on the SR-71 fuselage and wing adjacent to the model (figs. 18(c) and 18(d)). The extremely low-pressure region on top of the model is unrealistic and related to the fact that A502 is a potential flow code. Potential flow codes do not accurately handle separated flow. Instead, such codes accelerate flows around sharp corners; however, this influence on the pitching moment increment is small. The low-pressure region on the fuselage and wing adjacent to the model has the most significant effect on pitching moment. In the forward model position, this low-pressure region is forward of the moment reference location (F.S. 900) and, hence, reduces the nosedown pitching moment. For the aft model configuration, this low-pressure region combines with the low-pressure flow around the aft end of the canoe to increase the nosedown pitching moment.
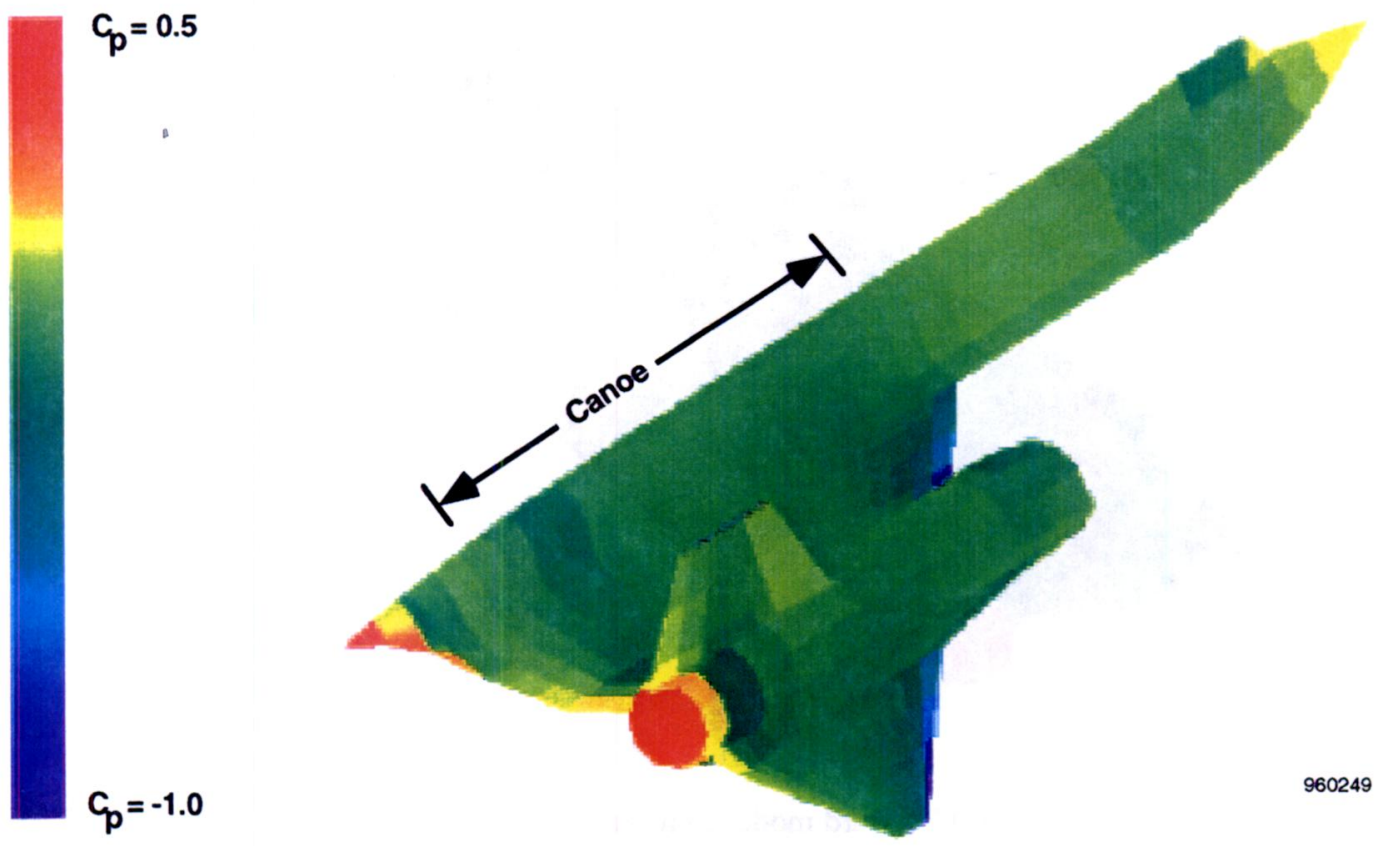

(a) Baseline SR-71 airplane.

Figure 18. A502 surface pressure maps at Mach 0.6 and $4^{\circ}$ angle of attack. 


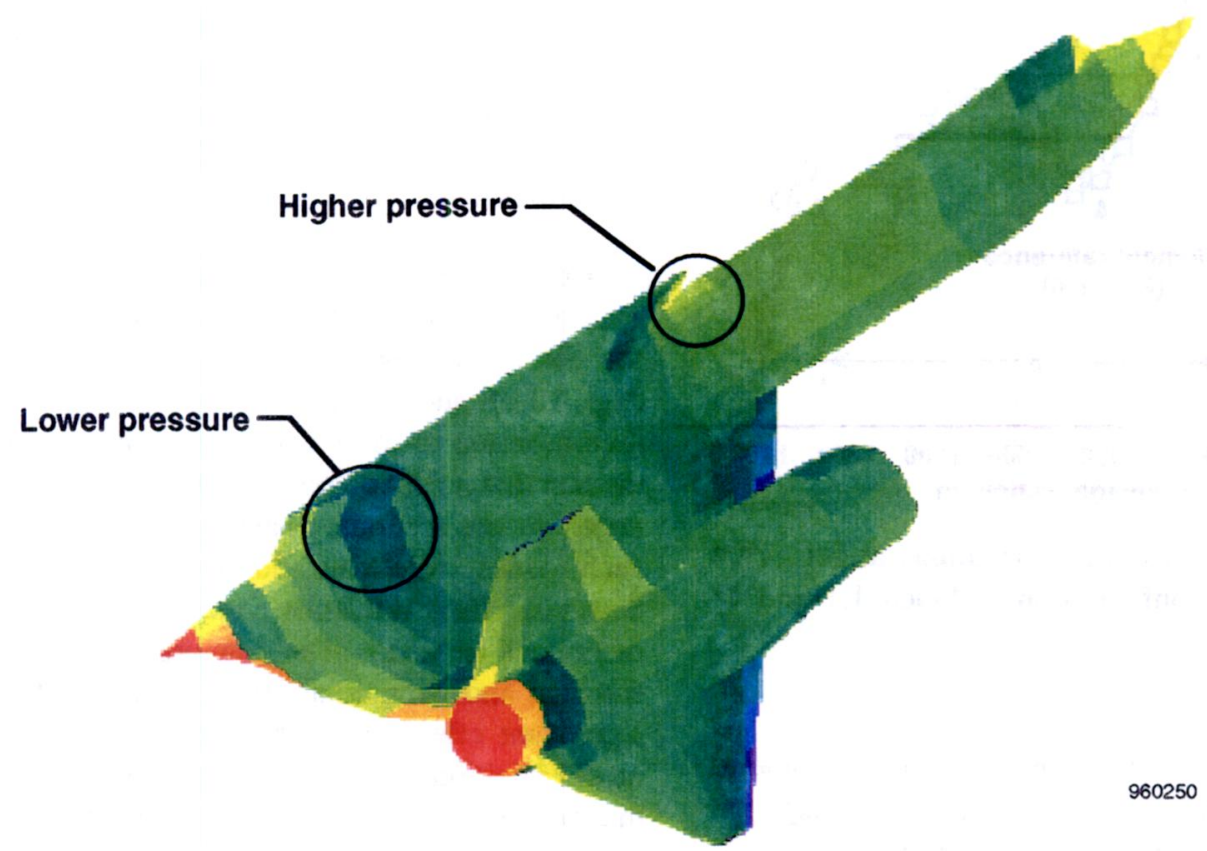

(b) Canoe-only configuration.

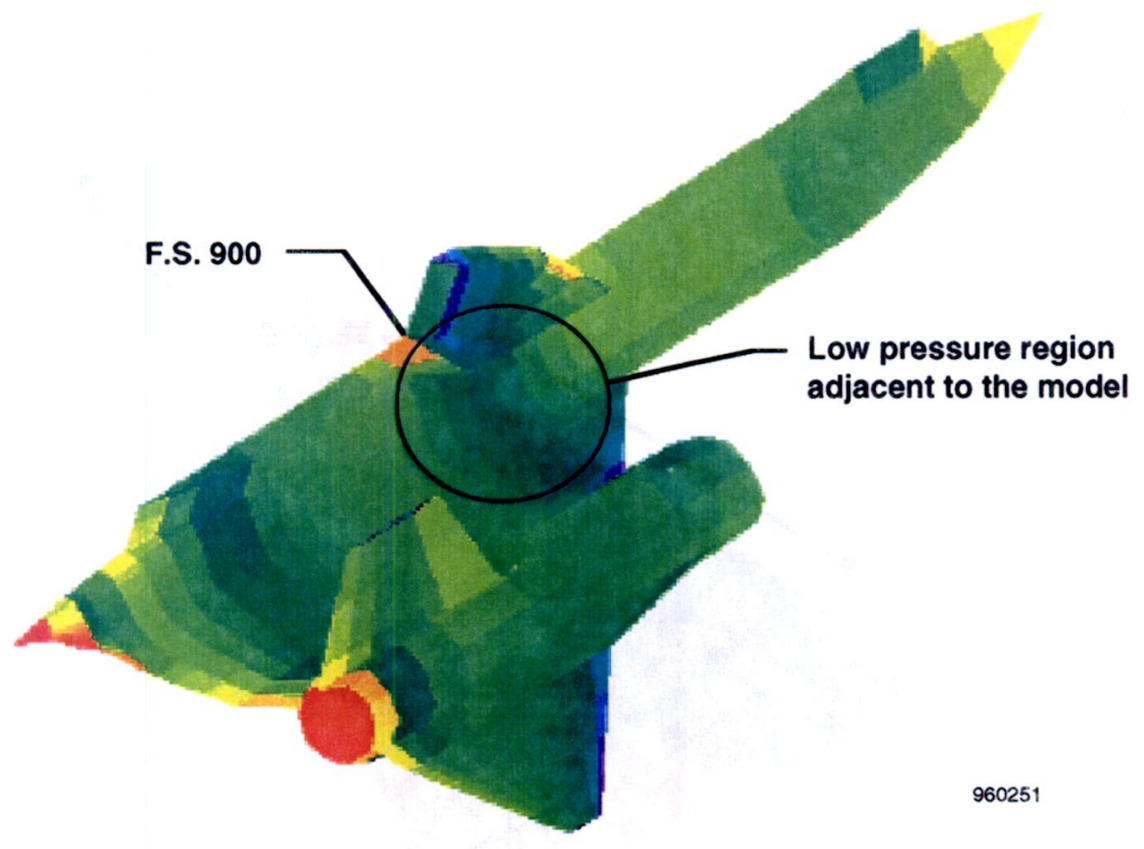

(c) Forward model configuration.

Figure 18. Continued. 


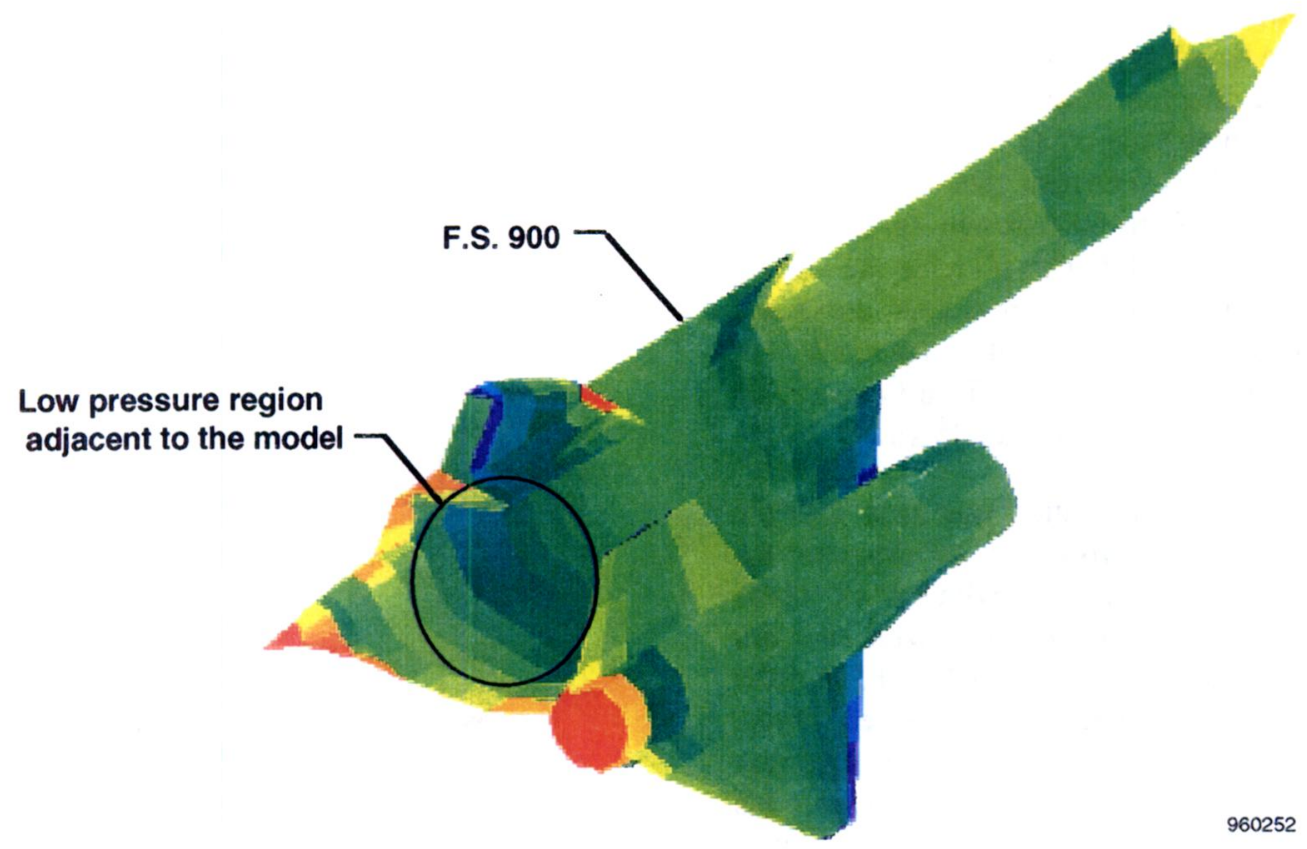

(d) Aft model configuration.

Figure 18. Concluded.

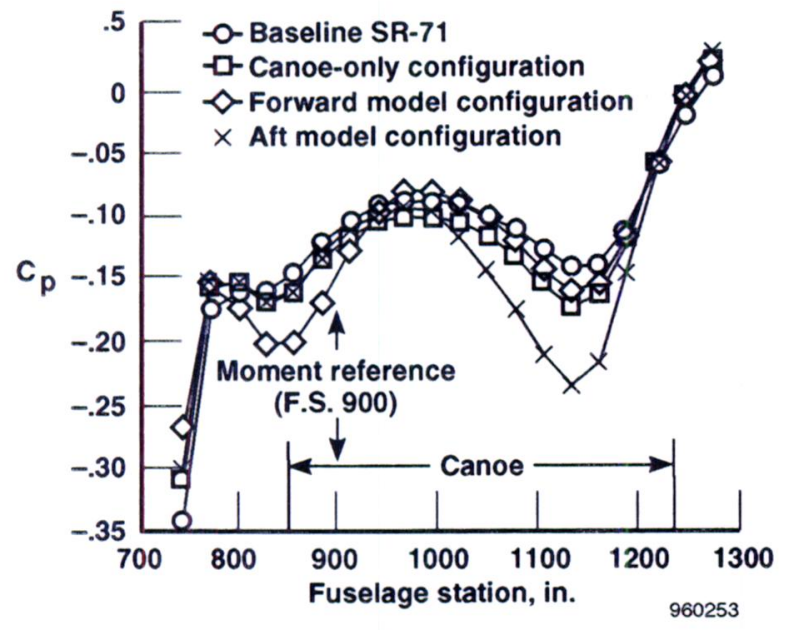

Figure 19. A502 wing pressure distributions at the 22-percent semispan station.

\section{Flight Simulation Control and Performance Analysis}

Flight simulations demonstrated that the additional pitching moment increment for the LASRE configuration would reduce airspeed and c.g. operating limits as a result of elevon hinge moment limits. Figure 20 shows the normal and modified SR-71 airspeed envelopes. The SR-71 control surfaces are actuated by two hydraulic systems. Safety of flight constraints require that the aircraft be controllable in $1-g$ flight with only one hydraulic system operational. The

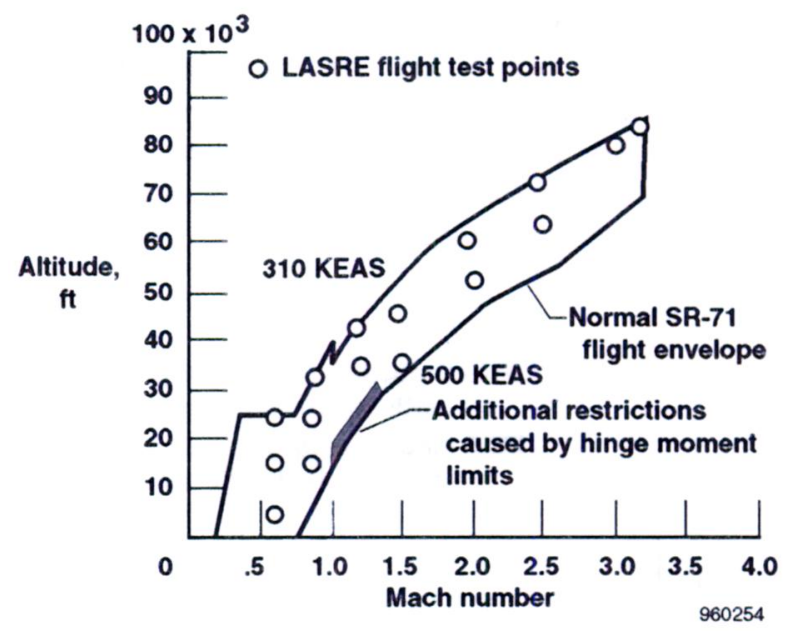

Figure 20. The LASRE flight envelope with restricted region caused by predicted hinge moment limits.

SR-71 surfaces are rigged such that the outboard elevons become hinge moment limited before the inboards. The LASRE vehicle was restricted to airspeeds below that which the outboard elevons would become hinge moment limited. On the one hand, the required LASRE flight test points do not occur in this restricted region. On the other hand, the restricted part of the envelope was no longer available for the transonic acceleration which results in a less fuel efficient acceleration. 
Figure 21 shows how the airspeed limits were derived. These limits were based on the outboard hinge moment being limited in a dive maneuver. In this scenario, the vehicle climbs to an altitude of $33,000 \mathrm{ft}$ at a constant Mach 0.9 followed by a constant rate dive. Constant descent rates from 1000 to $6000 \mathrm{ft} / \mathrm{min}$ are plotted in figure 21 for a 120,000 lbf aircraft with the c.g. at 24-percent m.a.c. The outboard actuators are hinge moment limited at equivalent airspeeds of approximately 465 to $475 \mathrm{kn}$. The inboard elevons do not become limited for at least another $25 \mathrm{kn}$.

The piloted, real-time simulation was used with the LASRE mass and drag properties to estimate the maximum Mach number attainable with the aft model configuration. The simulation was run with standard J-58 engines (Pratt \& Whitney, Palm Beach, Florida) and with engines upgraded for enhanced thrust performance. The majority of the thrust enhancement was derived from manually uptrimming the exhaust gas temperatures from Mach 1.0 to Mach 2.5. The entire pod weight was assumed to be $13,838 \mathrm{lb}$.

Figure 22 shows a level acceleration at an altitude of $25,000 \mathrm{ft}$ from Mach 0.75 to $450 \mathrm{KEAS}$ followed by a 450 KEAS climb at standard day atmospheric conditions. For operational reasons, the aircraft was required to cease testing and return to base when $20,000 \mathrm{lb}$ of fuel remained. This requirement includes $5000 \mathrm{lb}$ of unusable fuel which was needed as forward ballast to counter the additional aft-mounted weight of

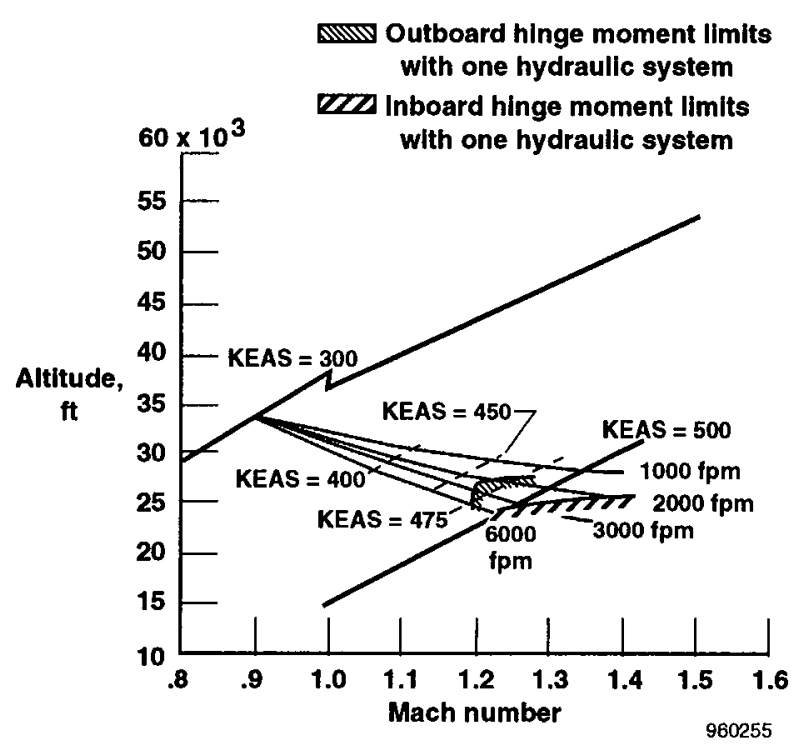

Figure 21. Airspeed limits in a dive maneuver caused by predicted outboard and inboard elevon hinge moment limits.

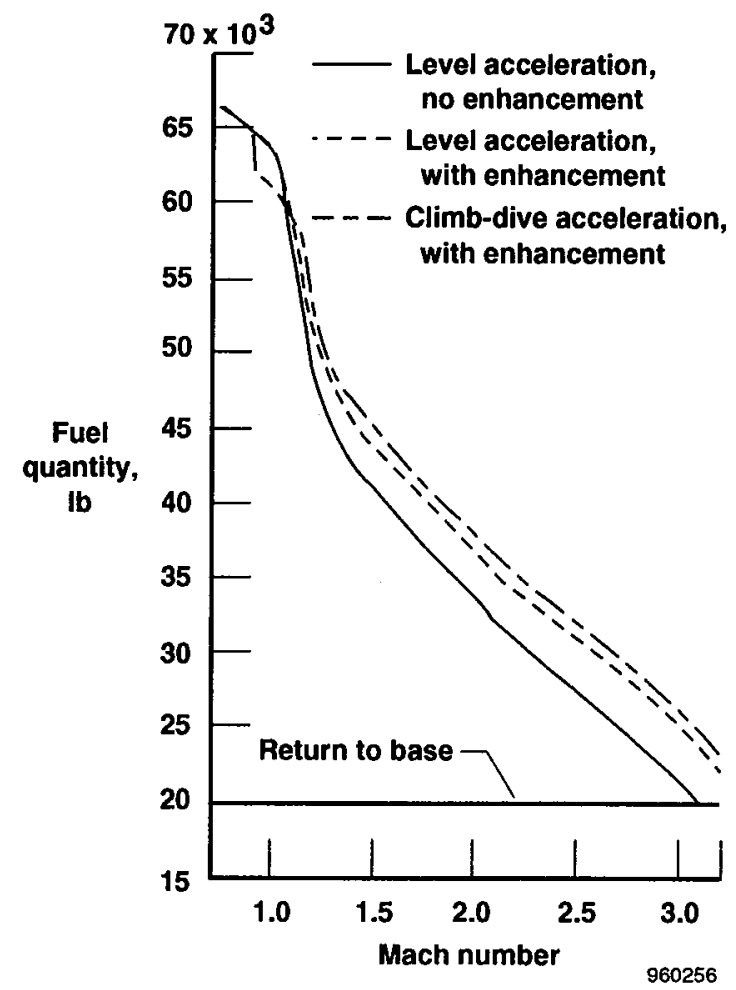

Figure 22. Performance simulation results for the LASRE configuration with and without thrust enhancement.

the aerospike pod. With thrust enhancement, the vehicle reached the desired Mach 3.2 with enough fuel remaining for approximately $2.5 \mathrm{~min}$ of cruise flight before having to return to base. Without enhancement the vehicle only reached Mach 3.09 before having to return to base.

Figure 22 also shows results using a transonic climb and dive maneuver. Starting at Mach 0.75 and an altitude of $25,000 \mathrm{ft}$, the vehicle accelerated at level altitude to Mach 0.9 for a constant Mach number climb to an altitude of $33,000 \mathrm{ft}$. At this point, a $3000 \mathrm{ft} / \mathrm{min}$ descent was begun. At an altitude of $26,000 \mathrm{ft}$, a 450 KEAS climb was initiated. Using thrust enhancement, the vehicle accelerated to Mach 3.2 with enough fuel remaining for $3.6 \mathrm{~min}$ of cruising flight before return to base. Hence, the climb and dive maneuver provided a small performance benefit in terms of fuel saved during the transonic portion of the acceleration.

\section{Concluding Remarks}

A series of wind-tunnel tests was completed in support of the Linear Aerospike SR-71 Experiment 
flight test program. These tests identified problems with the initial forward model configuration caused by an unexpected and excessive nosedown pitching moment. In addition, an aft model configuration that is expected to meet performance, stability, and control requirements during the flight test program was identified. The cause of the nosedown pitching moment was investigated by component buildup in the wind tunnel and with potential flow computational analyses. For supersonic Mach numbers, the nosedown pitching moment was caused by the combination of a high-pressure region forward of the canoe because of the bow shock and a low-pressure region aft of the canoe because of the expansion fans.

The canoe alone caused a significant nosedown pitching moment. Adding the model in the forward position increased the nosedown pitching moment; whereas, adding the model in the aft position negated the majority of the canoe-induced nosedown pitching moment. The additional trim drag and elevon actuator limits associated with the forward model configuration prevented the vehicle from being able to accelerate through the transonic speeds and, hence, made this configuration unacceptable. At subsonic Mach numbers, the nosedown pitching moment was worse for the aft model configuration. Potential flow analysis showed that this effect was caused by a low-pressure region created on the fuselage and wing adjacent to the model. The additional subsonic trim drag for the aft model configuration did not significantly affect performance; hence, the aft model configuration was shown to have acceptable drag and stability increments.

Ground-based flight simulations were critical in assessing the acceptability of these configurations.
These simulations focused on control authority and performance. Envelope restrictions were applied to the Linear Aerospike SR-71 Experiment configuration based on hinge moment limits. The real-time simulation was used to verify that the aircraft could be accelerated through the transonic Mach numbers. In addition, the maximum desired Mach number of Mach 3.2 was obtainable although only a few minutes of test time were available before having to cease testing and return to base.

\section{APPENDIX A FORWARD MODEL AERODYNAMIC INCREMENTS}

This appendix describes the aerodynamic model increments for the forward LASRE configuration (fig. 4). In creating these tables, conservative (read pessimistic) engineering judgements were always made in regard to LASRE performance, stability, and control. Data for this configuration are from the 4-ft wind tunnel for Mach 0.6 through Mach 3.2. A complete aerodynamic model was not obtained in the wind tunnel because this configuration was not acceptable for the LASRE experiment. The data that were obtained are presented here to document the aerodynamic characteristics of a payload mounted mostly forward of the pitching moment reference on top of the SR-71 airplane.

Tables A-1 through A-3 list the drag, lift, and pitching moment increments as a function of Mach number and wing reference plane angle of attack.

Table A-1. The $C_{D}$ increment caused by the LASRE pod with the model in the forward position.

\begin{tabular}{cccccccccccc}
\hline \hline & \multicolumn{10}{c}{ Angle of attack, deg } \\
\cline { 2 - 12 } number & $-2^{\circ}$ & $-1^{\circ}$ & $0^{\circ}$ & $1^{\circ}$ & $2^{\circ}$ & $3^{\circ}$ & $4^{\circ}$ & $5^{\circ}$ & $6^{\circ}$ & $7^{\circ}$ & $8^{\circ}$ \\
\hline 0.90 & 0.0039 & 0.0046 & 0.0050 & 0.0053 & 0.0054 & 0.0058 & 0.0059 & 0.0065 & 0.0066 & 0.0062 & 0.0082 \\
0.95 & 0.0062 & 0.0059 & 0.0054 & 0.0086 & 0.0090 & 0.0080 & 0.0100 & 0.0095 & 0.0104 & 0.0093 & 0.0104 \\
1.05 & 0.0082 & 0.0085 & 0.0089 & 0.0101 & 0.0109 & 0.0113 & 0.0121 & 0.0128 & 0.0128 & 0.0134 & 0.0126 \\
1.10 & 0.0088 & 0.0090 & 0.0103 & 0.0109 & 0.0115 & 0.0124 & 0.0128 & 0.0133 & 0.0133 & 0.0133 & 0.0123 \\
1.20 & 0.0082 & 0.0086 & 0.0094 & 0.0100 & 0.0105 & 0.0111 & 0.0113 & 0.0113 & 0.0114 & 0.0106 & 0.0095 \\
1.40 & 0.0066 & 0.0070 & 0.0074 & 0.0079 & 0.0077 & 0.0070 & 0.0076 & 0.0075 & 0.0068 & 0.0071 & 0.0066 \\
1.60 & 0.0058 & 0.0060 & 0.0065 & 0.0070 & 0.0068 & 0.0066 & 0.0068 & 0.0064 & 0.0060 & 0.0055 & 0.0055 \\
2.00 & 0.0055 & 0.0060 & 0.0058 & 0.0058 & 0.0055 & 0.0051 & 0.0051 & 0.0052 & 0.0048 & 0.0045 & 0.0042 \\
\hline \hline
\end{tabular}


Table A-2. The $C_{L}$ increment caused by the LASRE pod with the model in the forward position.

\begin{tabular}{|c|c|c|c|c|c|c|c|c|c|c|c|}
\hline \multirow{2}{*}{$\begin{array}{l}\text { Mach } \\
\text { number }\end{array}$} & \multicolumn{11}{|c|}{ Angle of attack, deg } \\
\hline & $-2^{\circ}$ & $-1^{\circ}$ & $0^{\circ}$ & $1^{\circ}$ & $2^{\circ}$ & $3^{\circ}$ & $4^{\circ}$ & $5^{\circ}$ & $6^{\circ}$ & $7^{\circ}$ & $8^{\circ}$ \\
\hline 0.90 & 0.0090 & 0.0080 & 0.0090 & 0.0090 & 0.0110 & 0.0090 & 0.0060 & 0.0080 & 0.0060 & 0.0060 & 0.0110 \\
\hline 0.95 & 0.0020 & 0.0130 & 0.0180 & 0.0070 & 0.0070 & 0.0130 & 0.0110 & 0.0070 & 0.0060 & 0.0080 & 0.0070 \\
\hline 1.05 & 0.0150 & 0.0170 & 0.0160 & 0.0200 & 0.0210 & 0.0200 & 0.0220 & 0.0210 & 0.0200 & 0.0150 & 0.0090 \\
\hline 1.10 & 0.0200 & 0.0210 & 0.0210 & 0.0250 & 0.0240 & 0.0260 & 0.0260 & 0.0230 & 0.0230 & 0.0220 & 0.0180 \\
\hline 1.20 & 0.0170 & 0.0150 & 0.0150 & 0.0180 & 0.0170 & 0.0180 & 0.0170 & 0.0140 & 0.0110 & 0.0040 & 0.0000 \\
\hline 1.40 & 0.0070 & 0.0060 & 0.0030 & 0.0040 & -0.0020 & -0.0040 & -0.0020 & -0.0010 & -0.0060 & -0.0020 & -0.0060 \\
\hline 1.60 & 0.0000 & 0.0000 & 0.0000 & 0.0000 & 0.0000 & 0.0000 & 0.0000 & 0.0000 & 0.0000 & 0.0000 & 0.0000 \\
\hline 2.00 & -0.0100 & -0.0100 & -0.0100 & -0.0100 & -0.0100 & -0.0100 & -0.0100 & -0.0100 & -0.0100 & -0.0100 & -0.0100 \\
\hline
\end{tabular}

Table A-3. The $C_{m}$ increment caused by the LASRE pod with the model in the forward position.

\begin{tabular}{|c|c|c|c|c|c|c|c|c|c|c|c|}
\hline \multirow[b]{2}{*}{$\begin{array}{c}\text { Mach } \\
\text { number }\end{array}$} & \multicolumn{11}{|c|}{ Angle of attack, deg } \\
\hline & $-2^{\circ}$ & $-1^{\circ}$ & $0^{\circ}$ & $1^{\circ}$ & $2^{\circ}$ & $3^{\circ}$ & $4^{\circ}$ & $5^{\circ}$ & $6^{\circ}$ & $7^{\circ}$ & $8^{\circ}$ \\
\hline 0.90 & -0.0039 & -0.0034 & -0.0039 & -0.0044 & -0.0041 & -0.0042 & -0.0042 & -0.0059 & -0.0068 & -0.0069 & -0.0111 \\
\hline 0.95 & -0.0027 & -0.0063 & -0.0075 & -0.0037 & -0.0038 & -0.0057 & -0.0050 & -0.0061 & -0.0064 & -0.0073 & -0.0092 \\
\hline 1.05 & -0.0072 & -0.0084 & -0.0101 & -0.0116 & -0.0130 & -0.0146 & -0.0160 & -0.0169 & -0.0162 & -0.0159 & -0.0147 \\
\hline 1.10 & -0.0077 & -0.0115 & -0.0129 & -0.0143 & -0.0160 & -0.0183 & -0.0208 & -0.0219 & -0.0222 & -0.0227 & -0.0225 \\
\hline 1.20 & -0.0129 & -0.0142 & -0.0160 & -0.0175 & -0.0190 & -0.0199 & -0.0199 & -0.0191 & -0.0197 & -0.0156 & -0.0137 \\
\hline 1.40 & -0.0163 & -0.0144 & -0.0147 & -0.0146 & -0.0132 & -0.0129 & -0.0128 & -0.0124 & -0.0115 & -0.0119 & -0.0119 \\
\hline 1.60 & -0.0160 & -0.0140 & -0.0130 & -0.0135 & -0.0130 & -0.0120 & -0.0105 & -0.0095 & -0.0090 & -0.0095 & -0.0095 \\
\hline 2.00 & -0.0055 & -0.0055 & -0.0050 & -0.0050 & -0.0045 & -0.0045 & -0.0045 & -0.0043 & -0.0040 & -0.0045 & -0.0050 \\
\hline
\end{tabular}

Table A-4 lists the side force, rolling moment, and yawing moment sideslip derivative increments. These data were obtained using sideslip sweeps at a set angle of attack. The approximate angle of attack for each Mach number is listed in the table.
Table A-4. Sideslip derivative increments caused by the LASRE pod with the model in the forward position.

\begin{tabular}{ccccc}
\hline \hline $\begin{array}{c}\text { Mach } \\
\text { number }\end{array}$ & $\begin{array}{c}\text { Angle of } \\
\text { attack, deg }\end{array}$ & $\begin{array}{c}\Delta C_{Y_{\beta}}, \\
\text { per deg }\end{array}$ & $\begin{array}{c}\Delta C_{l_{\beta}}, \\
\text { per deg }\end{array}$ & $\begin{array}{c}\Delta C_{n_{\beta}}{ }^{\prime} \\
\text { per deg }\end{array}$ \\
\hline 0.60 & $4.1^{\circ}$ & -0.00138 & 0.00031 & -0.00078 \\
0.95 & $5.2^{\circ}$ & -0.00055 & 0.00061 & -0.00101 \\
1.20 & $4.8^{\circ}$ & -0.00051 & 0.00089 & -0.00104 \\
2.00 & $4.6^{\circ}$ & -0.00008 & 0.00053 & -0.00076 \\
\hline \hline
\end{tabular}




\section{APPENDIX B AFT MODEL AERODYNAMIC INCREMENTS}

This appendix describes the aerodynamic model increments for the LASRE configuration with the model mounted in the aft position (fig. 5). In creating these tables, conservative engineering judgements were always made in regard to LASRE performance, stability, and control. Data for this configuration are from the $7-\mathrm{ft}$ wind tunnel for Mach 0.6 through Mach 1.6 and from the 4-ft wind tunnel for the higher Mach numbers.

Table B-1 lists the drag increment as a function of Mach number and wing reference plane angle of attack. Drag data at Mach 1.6 were not used because of an anomaly in these data. Mach 2 data were obtained in the first 4-ft wind tunnel test using the initial aft-mounted model configuration. This initial configuration has similar supersonic drag increments as the final aftmounted model configuration (fig. 6(a)). The Mach 2.5 and Mach 3.2 data were extrapolated from the Mach 2.0 data using engineering analysis to adjust for the changing wave drag. No viscous drag corrections were made to account for the fact that wind-tunnel Reynolds numbers were less than flight Reynolds numbers. The flight viscous drag component would be lower than the wind tunnel because of higher flight Reynolds numbers.
Because of the relatively small size of the aerospike pod, however, the viscous drag correction, at most, gives a reduction of six drag counts. In addition, these drag data do not include trim drag increments associated with the aft model configuration. Wind-tunnel data show that drag resulting from elevon deflection was not affected by the model in the aft configuration.

Table B-2 lists the lift increment as a function of Mach number and wing reference plane angle of attack. These data were obtained from the 7-ft tunnel and from Mach 0.6 to Mach 1.6. Hold last values were used at instances above Mach 1.6 and below Mach 0.6.

Table B-3 lists the pitching moment increment as a function of Mach number and wing reference plane angle of attack.

Table B-4 lists the pitching moment elevon effectiveness increment as a function of Mach number. Only the inboard elevons were adjusted in these tests because the outboard elevons were not expected to be affected by the LASRE pod. The elevons used in the 4-ft wind tunnel at Mach 3.2 had a 33-percent span reduction because of the aft end modification to accommodate the sting mount. The increment measured at Mach 3.2 was adjusted for a full-span elevon; however, no significant increment in elevon effectiveness was measured at Mach 3.2.

Table B-1. The $C_{I}$ increment caused by the LASRE pod with the model in the aft position.

\begin{tabular}{|c|c|c|c|c|c|c|c|c|c|c|c|}
\hline \multirow{2}{*}{$\begin{array}{l}\text { Mach } \\
\text { number }\end{array}$} & \multicolumn{11}{|c|}{ Angle of attack, deg } \\
\hline & $-2^{\circ}$ & $-1^{\circ}$ & $0^{\circ}$ & $1^{\circ}$ & $2^{\circ}$ & $3^{\circ}$ & $4^{\circ}$ & $5^{\circ}$ & $6^{\circ}$ & $7^{\circ}$ & $8^{\circ}$ \\
\hline 0.00 & 0.0038 & 0.0038 & 0.0040 & 0.0042 & 0.0041 & 0.0041 & 0.0036 & 0.0034 & 0.0032 & 0.0028 & 0.0033 \\
\hline 0.60 & 0.0038 & 0.0038 & 0.0040 & 0.0042 & 0.0041 & 0.0041 & 0.0036 & 0.0034 & 0.0032 & 0.0028 & 0.0033 \\
\hline 0.90 & 0.0102 & 0.0103 & 0.0105 & 0.0105 & 0.0103 & 0.0100 & 0.0095 & 0.0091 & 0.0087 & 0.0082 & 0.0087 \\
\hline 0.95 & 0.0143 & 0.0143 & 0.0143 & 0.0139 & 0.0132 & 0.0133 & 0.0129 & 0.0125 & 0.0117 & 0.0107 & 0.0109 \\
\hline 1.05 & 0.0128 & 0.0125 & 0.0120 & 0.0116 & 0.0111 & 0.0106 & 0.0101 & 0.0095 & 0.0091 & 0.0088 & 0.0085 \\
\hline 1.10 & 0.0122 & 0.0116 & 0.0112 & 0.0107 & 0.0101 & 0.0098 & 0.0094 & 0.0089 & 0.0084 & 0.0082 & 0.0081 \\
\hline 1.20 & 0.0097 & 0.0091 & 0.0089 & 0.0085 & 0.0083 & 0.0081 & 0.0078 & 0.0078 & 0.0075 & 0.0075 & 0.0073 \\
\hline 1.40 & 0.0066 & 0.0067 & 0.0066 & 0.0066 & 0.0067 & 0.0066 & 0.0065 & 0.0062 & 0.0058 & 0.0056 & 0.0054 \\
\hline 1.60 & 0.0060 & 0.0061 & 0.0060 & 0.0060 & 0.0059 & 0.0058 & 0.0056 & 0.0055 & 0.0051 & 0.0047 & 0.0045 \\
\hline 2.00 & 0.0049 & 0.0050 & 0.0047 & 0.0048 & 0.0044 & 0.0041 & 0.0040 & 0.0040 & 0.0037 & 0.0029 & 0.0025 \\
\hline 2.50 & 0.0046 & 0.0047 & 0.0044 & 0.0045 & 0.0041 & 0.0038 & 0.0037 & 0.0037 & 0.0034 & 0.0026 & 0.0022 \\
\hline 3.20 & 0.0043 & 0.0044 & 0.0041 & 0.0042 & 0.0038 & 0.0035 & 0.0034 & 0.0034 & 0.0031 & 0.0023 & 0.0019 \\
\hline
\end{tabular}


Table B-2. The $C_{L}$ increment caused by the LASRE pod with the model in the aft position.

\begin{tabular}{|c|c|c|c|c|c|c|c|c|c|c|c|}
\hline \multirow{2}{*}{$\begin{array}{c}\text { Mach } \\
\text { number }\end{array}$} & \multicolumn{11}{|c|}{ Angle of attack, deg } \\
\hline & $-2^{\circ}$ & $-1^{\circ}$ & $0^{\circ}$ & $1^{\circ}$ & $2^{\circ}$ & $3^{\circ}$ & $4^{\circ}$ & $5^{\circ}$ & $6^{\circ}$ & $7^{\circ}$ & $8^{\circ}$ \\
\hline 0.00 & 0.0046 & 0.0033 & 0.0052 & 0.0073 & 0.0017 & 0.0033 & -0.0035 & -0.0048 & -0.0057 & -0.0084 & -0.0068 \\
\hline 0.60 & 0.0046 & 0.0033 & 0.0052 & 0.0073 & 0.0017 & 0.0033 & -0.0035 & -0.0048 & -0.0057 & -0.0084 & -0.0068 \\
\hline 0.90 & -0.0010 & -0.0052 & -0.0063 & -0.0094 & -0.0100 & -0.0112 & -0.0144 & -0.0149 & -0.0165 & -0.0172 & -0.0133 \\
\hline 0.95 & -0.0224 & -0.0211 & -0.0220 & -0.0220 & -0.0192 & -0.0181 & -0.0190 & -0.0200 & -0.0213 & -0.0249 & -0.0287 \\
\hline 1.05 & -0.0180 & -0.0183 & -0.0183 & -0.0187 & -0.0170 & -0.0188 & -0.0200 & -0.0211 & -0.0235 & -0.0224 & -0.0184 \\
\hline 1.10 & -0.0190 & -0.0193 & -0.0164 & -0.0168 & -0.0175 & -0.0160 & -0.0168 & -0.0176 & -0.0188 & -0.0185 & -0.0216 \\
\hline 1.20 & -0.0120 & -0.0115 & -0.0110 & -0.0109 & -0.0106 & -0.0100 & -0.0097 & -0.0093 & -0.0103 & -0.0118 & -0.0144 \\
\hline 1.40 & -0.0099 & -0.0095 & -0.0094 & -0.0099 & -0.0098 & -0.0103 & -0.0120 & -0.0132 & -0.0133 & -0.0136 & -0.0084 \\
\hline 1.60 & -0.0069 & -0.0072 & -0.0072 & -0.0074 & -0.0074 & -0.0061 & -0.0068 & -0.0071 & -0.0081 & -0.0077 & -0.0081 \\
\hline 2.00 & -0.0069 & -0.0072 & -0.0072 & -0.0074 & -0.0074 & -0.0061 & -0.0068 & -0.0071 & -0.0081 & -0.0077 & -0.0081 \\
\hline 2.50 & -0.0069 & -0.0072 & -0.0072 & -0.0074 & -0.0074 & -0.0061 & -0.0068 & -0.0071 & -0.0081 & -0.0077 & -0.0081 \\
\hline 3.20 & -0.0069 & -0.0072 & -0.0072 & -0.0074 & -0.0074 & -0.0061 & -0.0068 & -0.0071 & -0.0081 & -0.0077 & -0.0081 \\
\hline
\end{tabular}

Table B-3. The $C_{m}$ increment caused by the LASRE pod with the model in the aft position.

\begin{tabular}{|c|c|c|c|c|c|c|c|c|c|c|c|}
\hline \multirow{2}{*}{$\begin{array}{l}\text { Mach } \\
\text { number }\end{array}$} & \multicolumn{11}{|c|}{ Angle of attack, deg } \\
\hline & $-2^{\circ}$ & $-1^{\circ}$ & $0^{\circ}$ & $1^{\circ}$ & $2^{\circ}$ & $3^{\circ}$ & $4^{\circ}$ & $5^{\circ}$ & $6^{\circ}$ & $7^{\circ}$ & $8^{\circ}$ \\
\hline 0.00 & -0.0086 & -0.0083 & -0.0085 & -0.0090 & -0.0087 & -0.0091 & -0.0084 & -0.0083 & -0.0079 & -0.0078 & -0.0074 \\
\hline 0.60 & -0.0086 & -0.0083 & -0.0085 & -0.0090 & -0.0087 & -0.0091 & -0.0084 & -0.0083 & -0.0079 & -0.0078 & -0.0074 \\
\hline 0.90 & -0.0105 & -0.0090 & -0.0090 & -0.0087 & -0.0093 & -0.0098 & -0.0092 & -0.0094 & -0.0091 & -0.0087 & -0.0071 \\
\hline 0.95 & 0.0038 & 0.0029 & 0.0027 & 0.0026 & 0.0010 & -0.0002 & -0.0006 & -0.0008 & -0.0008 & 0.0000 & 0.0010 \\
\hline 1.05 & 0.0032 & 0.0036 & 0.0031 & 0.0040 & 0.0039 & 0.0039 & 0.0040 & 0.0040 & 0.0041 & 0.0032 & 0.0032 \\
\hline 1.10 & 0.0030 & 0.0034 & 0.0027 & 0.0026 & 0.0027 & 0.0027 & 0.0020 & 0.0015 & 0.0013 & 0.0006 & 0.0015 \\
\hline 1.20 & -0.0013 & -0.0015 & -0.0022 & -0.0025 & -0.0027 & -0.0030 & -0.0033 & -0.0035 & -0.0036 & -0.0032 & -0.0026 \\
\hline 1.40 & -0.0017 & -0.0015 & -0.0016 & -0.0014 & -0.0012 & -0.0011 & -0.0008 & -0.0006 & -0.0011 & -0.0013 & -0.0019 \\
\hline 1.60 & -0.0011 & -0.0011 & -0.0011 & -0.0010 & -0.0008 & -0.0010 & -0.0010 & -0.0010 & -0.0007 & -0.0005 & -0.0003 \\
\hline 2.00 & 0.0000 & 0.0002 & 0.0001 & 0.0000 & 0.0000 & 0.0000 & 0.0000 & 0.0002 & 0.0005 & 0.0011 & 0.0014 \\
\hline 2.50 & 0.0016 & 0.0014 & 0.0008 & 0.0009 & 0.0011 & 0.0011 & 0.0014 & 0.0010 & 0.0008 & 0.0007 & 0.0011 \\
\hline 3.20 & 0.0029 & 0.0026 & 0.0024 & 0.0027 & 0.0024 & 0.0023 & 0.0021 & 0.0022 & 0.0023 & 0.0022 & 0.0024 \\
\hline
\end{tabular}

Table B-4. Elevon $C_{m}$ effectiveness increment caused by the LASRE pod with the model in the aft position.

\begin{tabular}{cc}
\hline $\begin{array}{c}\text { Mach } \\
\text { number }\end{array}$ & $\begin{array}{c}\Delta C_{m_{\delta e}} \\
\text { per deg }\end{array}$ \\
\hline 0.0 & 0.00017 \\
0.6 & 0.00017 \\
1.1 & 0.00028 \\
1.4 & 0.00008 \\
3.2 & 0.00000 \\
\hline \hline
\end{tabular}

Tables B-5 through B-7 list the side force, rolling moment, and yawing moment sideslip derivative increments.

Table B-8 lists the side force, rolling moment, and yawing moment rudder control derivative increments as a function of Mach number. 
Table B-5. The $C_{Y_{\beta}}$ increment (per deg) caused by the LASRE pod with the model in the aft position.

\begin{tabular}{|c|c|c|c|c|c|c|c|c|c|c|c|}
\hline \multirow[b]{2}{*}{$\begin{array}{c}\text { Mach } \\
\text { number }\end{array}$} & \multicolumn{11}{|c|}{ Angle of attack, deg } \\
\hline & $-2^{\circ}$ & $-1^{\circ}$ & $0^{\circ}$ & $1^{\circ}$ & $2^{\circ}$ & $3^{\circ}$ & $4^{\circ}$ & $5^{\circ}$ & $6^{\circ}$ & $7^{\circ}$ & $8^{\circ}$ \\
\hline 0.00 & -0.00092 & -0.00070 & -0.00080 & -0.00127 & -0.00064 & -0.00112 & -0.00106 & -0.00114 & -0.00120 & -0.00110 & -0.00114 \\
\hline 0.60 & -0.00092 & -0.00070 & -0.00080 & -0.00127 & -0.00064 & -0.00112 & -0.00106 & -0.00114 & -0.00120 & -0.00110 & -0.00114 \\
\hline 0.95 & -0.00144 & -0.00160 & -0.00133 & -0.00145 & -0.00142 & -0.00154 & -0.00127 & -0.00082 & -0.00073 & -0.00070 & -0.00040 \\
\hline 1.10 & -0.00027 & -0.00007 & 0.00012 & 0.00026 & 0.00045 & 0.00054 & 0.00067 & 0.00022 & 0.00083 & 0.00032 & 0.00105 \\
\hline 1.60 & -0.00215 & -0.00236 & -0.00233 & -0.00225 & -0.00219 & -0.00212 & -0.00241 & -0.00208 & -0.00216 & -0.00227 & -0.00199 \\
\hline 2.00 & -0.00095 & -0.00116 & -0.00113 & -0.00105 & -0.00099 & -0.00092 & -0.00121 & -0.00088 & -0.00096 & -0.00107 & -0.00079 \\
\hline 3.20 & -0.00080 & -0.00077 & -0.00052 & -0.00037 & -0.00044 & -0.00036 & -0.00034 & -0.00036 & -0.00030 & -0.00027 & -0.00012 \\
\hline
\end{tabular}

Table B-6. The $C_{l_{\beta}}$ increment (per deg) caused by the LASRE pod with the model in the aft position.

\begin{tabular}{cccccccccccc}
\hline \hline & \multicolumn{10}{c}{ Angle of attack, deg } \\
\cline { 2 - 12 } $\begin{array}{c}\text { Mach } \\
\text { number }\end{array}$ & $-2^{\circ}$ & $-1^{\circ}$ & $0^{\circ}$ & $1^{\circ}$ & $2^{\circ}$ & $3^{\circ}$ & $4^{\circ}$ & $5^{\circ}$ & $6^{\circ}$ & $7^{\circ}$ & $8^{\circ}$ \\
\hline 0.00 & 0.00023 & 0.00023 & 0.00023 & 0.00022 & 0.00023 & 0.00027 & 0.00025 & 0.00031 & 0.00023 & 0.00037 & 0.00034 \\
0.60 & 0.00023 & 0.00023 & 0.00023 & 0.00022 & 0.00023 & 0.00027 & 0.00025 & 0.00031 & 0.00023 & 0.00037 & 0.00034 \\
0.95 & 0.00028 & 0.00024 & 0.00026 & 0.00028 & 0.00032 & 0.00035 & 0.00031 & 0.00035 & 0.00031 & 0.00040 & 0.00048 \\
1.10 & 0.00051 & 0.00048 & 0.00043 & 0.00044 & 0.00038 & 0.00034 & 0.00025 & 0.00019 & 0.00020 & 0.00019 & 0.00038 \\
1.60 & 0.00026 & 0.00030 & 0.00030 & 0.00030 & 0.00032 & 0.00031 & 0.00029 & 0.00032 & 0.00031 & 0.00030 & 0.00032 \\
2.00 & 0.00021 & 0.00025 & 0.00025 & 0.00024 & 0.00026 & 0.00026 & 0.00023 & 0.00027 & 0.00025 & 0.00024 & 0.00026 \\
3.20 & 0.00010 & 0.00010 & 0.00010 & 0.00009 & 0.00009 & 0.00009 & 0.00007 & 0.00007 & 0.00008 & 0.00008 & 0.00009 \\
\hline \hline
\end{tabular}

Table B-7. The $C_{n_{\beta}}$ increment (per deg) caused by the LASRE pod with the model in the aft position.

\begin{tabular}{crrrrrcccccc}
\hline \hline & \multicolumn{10}{c}{ Angle of attack, deg } \\
\cline { 2 - 11 } $\begin{array}{c}\text { Mach } \\
\text { number }\end{array}$ & \multicolumn{1}{c}{$-^{\circ}$} & $-1^{\circ}$ & $0^{\circ}$ & $1^{\circ}$ & $2^{\circ}$ & $3^{\circ}$ & $4^{\circ}$ & $5^{\circ}$ & $6^{\circ}$ & $7^{\circ}$ & $8^{\circ}$ \\
\hline 0.00 & -0.00015 & -0.00016 & -0.00014 & -0.00020 & -0.00018 & -0.00019 & -0.00018 & -0.00016 & -0.00014 & -0.00015 & -0.00020 \\
0.60 & -0.00015 & -0.00016 & -0.00014 & -0.00020 & -0.00018 & -0.00019 & -0.00018 & -0.00016 & -0.00014 & -0.00015 & -0.00020 \\
0.95 & 0.00018 & 0.00016 & 0.00012 & 0.00013 & 0.00012 & 0.00014 & 0.00008 & -0.00005 & -0.00011 & -0.00011 & -0.00014 \\
1.10 & -0.00038 & -0.00052 & -0.00064 & -0.00073 & -0.00076 & -0.00078 & -0.00078 & -0.00078 & -0.00075 & -0.00071 & -0.00079 \\
1.60 & 0.00029 & 0.00035 & 0.00038 & 0.00041 & 0.00045 & 0.00049 & 0.00051 & 0.00052 & 0.00055 & 0.00059 & 0.00058 \\
2.00 & -0.00003 & 0.00003 & 0.00006 & 0.00009 & 0.00013 & 0.00017 & 0.00019 & 0.00020 & 0.00023 & 0.00027 & 0.00026 \\
3.20 & -0.00015 & -0.00017 & -0.00021 & -0.00023 & -0.00019 & -0.00020 & -0.00016 & -0.00011 & -0.00012 & -0.00010 & -0.00011 \\
\hline \hline
\end{tabular}


Table B-8. Rudder control derivative increments caused by the LASRE pod with the model in the aft position.

\begin{tabular}{cccc}
\hline $\begin{array}{c}\text { Mach } \\
\text { number }\end{array}$ & $\begin{array}{c}\Delta C_{Y_{\delta r}{ }^{\prime}} \\
\text { per deg }\end{array}$ & $\begin{array}{c}\Delta C_{l_{\delta r}{ }^{\prime}} \\
\text { per deg }\end{array}$ & $\begin{array}{c}\Delta C_{n_{\delta r}{ }^{\prime}} \\
\text { per deg }\end{array}$ \\
\hline 0.0 & -0.0001148 & 0.0000552 & 0.0000597 \\
0.6 & -0.0001148 & 0.0000552 & 0.0000597 \\
1.1 & -0.0006052 & 0.0000409 & 0.0003059 \\
1.6 & 0.0000000 & 0.0000238 & 0.0000000 \\
3.2 & 0.0000000 & 0.0000000 & 0.0000000 \\
\hline \hline
\end{tabular}

\section{$\underline{\text { References }}$}

${ }^{1}$ Martinez, A., Aerodynamic Nozzle Study, vol. 1, Rocketdyne Final Report R-6582, North American Aviation, Inc., Los Angeles, California, July 15, 1966.

${ }^{2}$ Martinez, A., Aerodynamic Nozzle Study, Slipstream Studies, vol. III, Rocketdyne Interim Report R-6273, North American Aviation, Inc., Los Angeles, California, July $31,1965$.

${ }^{3}$ Meyer, J.E., McMaster, J.R., and Moody, R.L., Handling Qualities of the SR-71, Lockheed Aircraft
Corporation, Report no. SP-508, Burbank, California, Oct. 29, 1964.

${ }^{4}$ Saaris, Gary R., A502I User's Manual - PAN AIR Technology Program for Solving Problems of Potential Flow about Arbitrary Configurations, Document no. D6-54703, The Boeing Company, Seattle, Washington, Feb. 1992.

5Johnson, F.T., Samant, S.S., Bieterman, M.B., Melvin, R.G., Young, D.P., Bussoletti, J.E., and Hilmes, C.L., TranAir: A Full-Potential, Solution-Adaptive, Rectangular Grid Code for Predicting Subsonic, Transonic, and Supersonic Flows About Arbitrary Configurations-Theory Document, NASA CR 4348, 1992.

${ }^{6}$ Johnson, F.T., Samant, S.S., Bieterman, M.B., Melvin, R.G., Young, D.P., Bussoletti, J.E., and Hilmes, C.L., TranAir: A Full-Potential Solution-Adaptive, Rectangular Grid Code for Predicting Subsonic, Transonic, and Supersonic Flows About Arbitrary Configurations-User's Manual, NASA CR 4349, 1992.

${ }^{7}$ Meyer, J.E. and Campbell, D.H., The YF-12A as a Prototype Inlet Flight Test Bed, Lockheed Aircraft Corporation - Advanced Development Projects, Report no. SP-4137A, Burbank, California, Mar. 15, 1974. 
Public reporting burden for this collection of information is estimated to average 1 hour per response, including the time for reviewing instructions, searching existing data sources. gathering and maintaining the data needed, and completing and reviewing the collection of information. Send comments regarding this burden estimate or any other aspect of this collection of intormation, including suggestions for reducing this burden, to Washington Headquarters Services, Directorate for Information Operations and Reports, 1215 Jefferson Davis Highway, Suite 1204, Arlington, VA 22202-4302, and to the Office of Management and Budget, Paperwork Reduction Project (0704-0188), Washington, DC 20503.

1. AGENCY USE ONLY (Leave blank)

2. REPORT DATE

3. REPORT TYPE AND DATES COVERED

June 1996

Technical Memorandum

4.TITLE AND SUBTITLE

Wind-Tunnel Development of an SR-71 Aerospike Rocket Flight Test Configuration

6. AUTHOR(S)

Timothy R. Moes, Brent R. Cobleigh, Timothy R. Connors, Timothy H.

Cox, Stephen C. Smith, and Norm Shirakata

7. PERFORMING ORGANIZATION NAME(S) AND ADDRESS(ES)

8. PERFORMING ORGANIZATION

REPORT NUMBER

NASA Dryden Flight Research Center

P.O. Box 273

Edwards, California 93523-0273

$\mathrm{H}-2108$

9. SPONSORING/MONOTORING AGENCY NAME(S) AND ADDRESS(ES)

National Aeronautics and Space Administration

Washington, DC 20546-0001

WU 505-68-52

5. FUNDING NUMBERS

10. SPONSORING/MONTORING AGENCY REPORT NUMBER

NASA TM-4749

\section{SUPPLEMENTARY NOTES}

Presented as AIAA 96-2409 at the 14th Applied Aerodynamics Conference, New Orleans, Louisiana, June 17-20, 1996. Timothy R.

Moes, Brent R. Cobleigh, Timothy R. Conners, and Timothy H. Cox, NASA Dryden Flight Research Center, Edwards, CA; Stephen C.

Smith, NASA Ames Research Center, Moffett Field, CA; Norm Shirakata, Lockheed-Martin Skunk Works, Palmdale, CA.

12a. DISTRIBUTION/AVAILABILITY STATEMENT

12b. DISTRIBUTION CODE

Unclassified-Unlimited

Subject Category 02

13. ABSTRACT (Maximum 200 words)

A flight experiment has been proposed to investigate the performance of an aerospike rocket motor installed in a lifting body configuration. An SR-71 airplane would be used to carry the aerospike configuration to the desired flight test conditions. Wind-tunnel tests were completed on a 4-percent scale SR-71 airplane with the aerospike pod mounted in various locations on the upper fuselage. Testing was accomplished using sting and blade mounts from Mach 0.6 to Mach 3.2. Initial test objectives included assessing transonic drag and supersonic lateral-directional stability and control. During these tests, flight simulations were run with wind-tunnel data to assess the acceptability of the configurations. Early testing demonstrated that the initial configuration with the aerospike pod near the SR-71 center of gravity was unsuitable because of large nosedown pitching moments at transonic speeds. The excessive trim drag resulting from accommodating this pitching moment far exceeded the excess thrust capability of the airplane. Wind-tunnel testing continued in an attempt to find a configuration suitable for flight test. Multiple configurations were tested. Results indicate that an aft-mounted model configuration possessed acceptable performance, stability, and control characteristics.

\section{SUBJECT TERMS}

Aerodynamic models; Aerospike; Flight simulations; Rocket; SR-71 airplane; Wind tunnel

17. SECURITY CLASSIFICATION OF REPORT

Unclassified

NSN 7540-01-280-5500
Available from the NASA Center for AeroSpace Information, 800 Elkridge Landing Road, Linthicum Heights, MD 21090; (301)621-0390
15. NUMBER OF PAGES

27

16. PRICE CODE A03

20. LIMITATION OF ABSTRACT

Unlimited

Standard Form 298 (Rev. 2-89) Prescribed by ANSI Std. Z39-18 

National Aeronautics and

Space Administration

Code JTT

Washington, D.C. 20546-0001

SPECIAL FOURTH-CLASS RATE POSTAGE AND FEES PAID NASA

USA

Official Business

Penalty for Private Use, $\$ 300$ 